\title{
Effect of strain on generalized stacking fault energies and plastic deformation modes in fcc-hcp polymorphic high-entropy alloys: A first-principles investigation
}

\author{
Stephan Schönecker $\odot,{ }^{1, *}$ Wei Li, ${ }^{2}$ Levente Vitos, ${ }^{1,3,2}$ and Xiaoqing $\mathrm{Li}^{1, \dagger}$ \\ ${ }^{1}$ Unit of Properties, Department of Materials Science and Engineering, KTH-Royal Institute of Technology, Stockholm SE-10044, Sweden \\ ${ }^{2}$ Department of Physics and Astronomy, Division of Materials Theory, Uppsala University, Box 516, SE-75120, Uppsala, Sweden \\ ${ }^{3}$ Research Institute for Solid State Physics and Optics, Wigner Research Center for Physics, Budapest H-1525, P.O. Box 49, Hungary
}

(Received 15 April 2021; accepted 1 July 2021; published 26 July 2021)

\begin{abstract}
The generalized stacking fault energy (GSFE) is a material property that can provide invaluable insights into describing nanoscale plasticity phenomena in crystalline materials. Lattice strains have been suggested to influence such phenomena. Here, the GSFE curves for sequential faulting pathways in dual phase [face-centered cubic (fcc) and hexagonal close-packed (hcp)] $\mathrm{Cr}_{20} \mathrm{Mn}_{20} \mathrm{Fe}_{20} \mathrm{Co}_{20} \mathrm{Ni}_{20}, \mathrm{Cr}_{25} \mathrm{Fe}_{25} \mathrm{Co}_{25} \mathrm{Ni}_{25}, \mathrm{Cr}_{20} \mathrm{Mn}_{20} \mathrm{Fe}_{34} \mathrm{Co}_{20} \mathrm{Ni}_{6}$, $\mathrm{Cr}_{20} \mathrm{Mn}_{20} \mathrm{Fe}_{30} \mathrm{Co}_{20} \mathrm{Ni}_{10}$, and $\mathrm{Cr}_{10} \mathrm{Mn}_{30} \mathrm{Fe}_{50} \mathrm{Co}_{10}$ high-entropy alloys are investigated on $\{111\}_{\mathrm{fcc}}$ and $(0002)_{\text {hcp }}$ close-packed planes using density-functional calculations. The dependence of GSFEs on imposed volumetric and longitudinal lattice strains is studied in detail for $\mathrm{Cr}_{20} \mathrm{Mn}_{20} \mathrm{Fe}_{20} \mathrm{Co}_{20} \mathrm{Ni}_{20}$ and $\mathrm{Cr}_{10} \mathrm{Mn}_{30} \mathrm{Fe}_{50} \mathrm{Co}_{10}$. The competition between various plastic deformation modes is discussed for both phases based on effective energy barriers determined from the calculated GSFEs and compared with experimentally observed deformation mechanisms. The intrinsic stacking fault energy, unstable stacking fault energy, and unstable twinning fault energy are found to be closely related in how they are affected by applied strain. The ratio of two of these planar fault energies can thus serve as characteristic material property. An inverse relationship between the intrinsic stacking fault energy in the hcp phase and the axial ratio $(c / a)_{\mathrm{hcp}}$ is revealed and explained via band theory.
\end{abstract}

DOI: 10.1103/PhysRevMaterials.5.075004

\section{INTRODUCTION}

The research field of high-entropy alloys (HEAs) has attracted significant attention since these were proposed by Yeh et al. [1] and Cantor et al. [2]. Some developed HEAs possess excellent properties, e.g., good wear and corrosion resistance, high strength and fracture toughness, good irradiation resistance, high hardness, or good thermal conductivity [3-8]. In instances where compound formation and phase separation are suppressed, HEAs typically crystallize in simple structures, most frequently face-centered cubic (fcc) or body-centered cubic. Few single-phase HEAs with hexagonal close-packed (hcp) structure were reported, such as DyGdHoTbY composed of only rare earth elements [9].

Polymorphic HEAs are composed of two or more solid-solution phases with different crystal structures. A coexistence of fcc and hcp phases has been reported in a wide variety of HEAs, some of which show certain noteworthy mechanical properties [5,7,8,10,11]. A pressureinduced transformation from the fcc phase to the hcp

\footnotetext{
*stesch@kth.se

†xiaoqli@kth.se
}

Published by the American Physical Society under the terms of the Creative Commons Attribution 4.0 International license. Further distribution of this work must maintain attribution to the author(s) and the published article's title, journal citation, and DOI. Funded by Bibsam. phase occurs in $\mathrm{Cr}_{20} \mathrm{Mn}_{20} \mathrm{Fe}_{20} \mathrm{Co}_{20} \mathrm{Ni}_{20}$ (Cantor alloy) and $\mathrm{Cr}_{25} \mathrm{Fe}_{25} \mathrm{Co}_{25} \mathrm{Ni}_{25}$ at room temperature (RT) [12-14]. Because the phase transformation is sluggish upon both pressurization and depressurization, application of pressure may serve as processing route for tuning the phase fractions in these dual-phase HEAs. Besides, an fcc to hcp phase transformation in $\mathrm{Cr}_{20} \mathrm{Mn}_{20} \mathrm{Fe}_{20} \mathrm{Co}_{20} \mathrm{Ni}_{20}$ occurs under high-pressure torsion at $77 \mathrm{~K}$, but not at RT [10]. Tailoring phase stability in HEAs towards exhibiting a transformation-induced fcc to hcp phase transition resulted in the development of $\mathrm{Cr}_{20} \mathrm{Mn}_{20} \mathrm{Fe}_{34} \mathrm{Co}_{20} \mathrm{Ni}_{6}$ and $\mathrm{Cr}_{10} \mathrm{Mn}_{30} \mathrm{Fe}_{50} \mathrm{Co}_{10}$ [5,11]. Both two-phase HEAs show superior strength-ductility combinations than mono-phase counterparts owing to several active hardening mechanisms. These recent experimental progresses motivate to explore and understand the fundamental deformation mechanisms underlying crystal plasticity in advanced polymorphic HEAs.

The intrinsic stacking fault (ISF) energy is an experimentally and theoretically accessible material property often claimed to be correlated with the predominantly active plastic deformation mode in the fcc phase of metals and alloys. The ISF energy further determines the equilibrium separation of partial dislocations and affects the propensity for dislocation cross slip. The traditional notion is that dislocation glide is favored in fcc metals and alloys with medium to high ISF energy, whereas deformation twinning is typical of low to medium ISF materials, and hcp martensitic transformation prevails for low ISF energy [15,16]. However, $\mathrm{Ag}\left(16 \mathrm{~mJ} / \mathrm{m}^{2}\right)$ and $\mathrm{Ir}\left(480 \mathrm{~mJ} / \mathrm{m}^{2}\right)$ are examples for metals with low ISF energy and high ISF energy $[17,18]$, respectively, which both 
twin under ordinary loading conditions at RT [19-22]. Furthermore, $\mathrm{Al}\left(166 \mathrm{~mJ} / \mathrm{m}^{2}[17,18]\right)$ does ordinarily not twin at high strain rates and/or low temperatures unlike $\mathrm{Cu}$ and $\mathrm{Ni}$, but $\mathrm{Al}$ does twin in nanocrystalline form [23,24]. Obviously, the ISF energy alone does not provide a complete picture of the prevailing plastic deformation mode.

Theory and simulations of plasticity in crystalline materials often resort to the theoretical concept of the generalized stacking fault energy (GSFE) [25]. Broadly, it describes the energy penalty due to shearing parallel slip planes in a certain slip direction. The stable and unstable stacking fault energies on GSFE curves contain sufficient fundamental information in determining nanoscale plastic deformation modes in the thermally nonactivated limit. The GSFE was employed to describe nucleation mechanisms of deformation twins [26], the competition of plastic deformation mechanisms [27-31], twinning stresses [32], solid-solution strengthening [33], and dislocation nucleation [34]. At present, GSFE curves are not experimentally accessible. First-principles calculations and atomistic simulations are thus the primary tools to obtain them.

Strain is an external parameter known to affect the ISF energy and GSFE curves. For instance, recent first-principles studies demonstrated that already mild strain can lead to large changes of the GSFE in fcc $\mathrm{Cu}, \mathrm{Ni}$, and $\mathrm{Al}$ [35-37]. Zhang et al. suggested that lattice strain in hcp $\mathrm{Mg}$ and binary $\mathrm{Mg}$ alloys alters dislocation core structure and preferred slip systems [38]. Understanding the implications of how the GSFE depends on strain is particularly important for mechanical properties, plasticity, and microstructural evolution of metals and alloys subject to high pressure, in shock-loading conditions, during severe plastic deformation or high strain-rate deformation, and in nanocrystalline systems.

In this work, we are concerned with a density-functional theory (DFT) investigation of GSFEs in the five polymorphic HEAs $\mathrm{Cr}_{20} \mathrm{Mn}_{20} \mathrm{Fe}_{20} \mathrm{Co}_{20} \mathrm{Ni}_{20}, \quad \mathrm{Cr}_{25} \mathrm{Fe}_{25} \mathrm{Co}_{25} \mathrm{Ni}_{25}$, $\mathrm{Cr}_{20} \mathrm{Mn}_{20} \mathrm{Fe}_{34} \mathrm{Co}_{20} \mathrm{Ni}_{6}, \quad \mathrm{Cr}_{20} \mathrm{Mn}_{20} \mathrm{Fe}_{30} \mathrm{Co}_{20} \mathrm{Ni}_{10}, \quad$ and $\mathrm{Cr}_{10} \mathrm{Mn}_{30} \mathrm{Fe}_{50} \mathrm{Co}_{10}$ in their compositionally identical fcc and hep phases. We concentrate on GSFEs associated with dislocation slip on $\{111\}_{\mathrm{fcc}}$ and (0002) hcp close-packed planes. Besides often being an easy glide system in hcp metals and alloys [17,39], further reasons motivated the present focus on basal slip. While a martensitic transformation from the fcc phase to the hcp phase is a primary deformation mechanism in several of the considered alloys, a reverse hcp to fcc martensitic transformation was observed in $\mathrm{Cr}_{10} \mathrm{Mn}_{30} \mathrm{Fe}_{50} \mathrm{Co}_{10}$ and attributed to basal slip [40]. The theory of plastic deformation modes presented below enables direct comparison between the fcc and hcp cases. For a comprehensive picture of dislocation slip in the hcp phase of these alloys, it will be important to consider slip on prism and pyramidal planes in future work.

After summarizing the necessary methodological and computational details in Sec. II, we present and discuss our results in Sec. III. We begin with the GSFE of all considered alloys in the absence of superimposed strain. $\mathrm{Cr}_{20} \mathrm{Mn}_{20} \mathrm{Fe}_{20} \mathrm{Co}_{20} \mathrm{Ni}_{20}$ and $\mathrm{Cr}_{10} \mathrm{Mn}_{30} \mathrm{Fe}_{50} \mathrm{Co}_{10}$ are in the focus of a detailed study on how homogeneous volumetric and longitudinal strains influence the GSFEs in both close-packed phases. To calculate GSFEs relevant for high pressure and shock conditions, strains as large as $\pm 10 \%$ are considered. We draw upon effective energy barriers derived from the calculated GSFEs to discuss the competition between various plastic deformation modes and compare the outcome with experimentally observed deformation mechanisms. We demonstrate that strain-dependent stacking fault energies and their zero-strain derivatives follow universal scaling rules closely. An approximately inverse linear relationship between the axial ratio $(c / a)_{\mathrm{hcp}}$ and ISF energy in the hcp phases is revealed and explained. Section IV concludes.

\section{METHODOLOGICAL AND COMPUTATIONAL DETAILS}

\section{A. GSFE and faulting pathways}

Let $E\left(\left\{\boldsymbol{u}_{i}\right\}\right)$ be a potential energy function associated with planar faults created by simple alias shear [41], where integer $i$ labels consecutive stacking planes and $\boldsymbol{u}_{i}$ is the relative shear displacement vector between planes $i$ and $i-1$. We consider the GSFE $\gamma(\eta)$ as a function of the total displacement $\eta \geqslant 0$ (dimensionless scalar),

$$
\gamma(\eta)=\frac{E\left(\left\{\boldsymbol{u}_{i}\right\}\right)-E_{\text {perfect }}}{A},
$$

for sequential fault pathways on close-packed planes. $E_{\text {perfect }} \equiv E\left(\left\{\boldsymbol{u}_{i}=\mathbf{0}\right\}\right)$ is the energy of the fault-free fcc or hcp lattice and $A$ is the fault area. Fault pathway prescriptions introduced next relate relative shear displacements to total displacements.

In fcc crystals, we consider the usual $a_{\mathrm{fcc}} / 2[10 \overline{1}](111)_{\mathrm{fcc}}$ slip system where a perfect lattice dislocation can dissociate into two Shockley partials with Burgers vectors $\boldsymbol{b}_{\mathrm{p} 1}^{\mathrm{fcc}}=$ $a_{\mathrm{fcc}} / 6[11 \overline{2}]_{\mathrm{fcc}}$ and $\boldsymbol{b}_{\mathrm{p} 2}^{\mathrm{fcc}}=a_{\mathrm{fcc}} / 6[2 \overline{1} \overline{1}]_{\mathrm{fcc}} \cdot a_{\mathrm{fcc}}$ is the fcc lattice parameter. The stacking sequence of (111) fcc close-packed planes is ... $\mathrm{ABC} \ldots$, where the labels $\mathrm{A}$ through $\mathrm{C}$ correspond to the three possible atomic positions in a (111) fcc plane [Fig. 1(a)]. Without loss of generality, atoms in plane $i=1$ assume the A position, those in plane $i=2$ the B position, and so on. We examine the GSFE by applying displacement vectors as

$$
\begin{aligned}
\boldsymbol{u}_{i \geqslant 1} & =[(x+1) H(x+1)-x H(x)] \boldsymbol{b}_{\mathrm{p} 1}^{\mathrm{fcc}}, \\
x & =\eta-i, \\
\boldsymbol{u}_{i \leqslant 0} & =\mathbf{0},
\end{aligned}
$$

which is illustrated in Fig. 2. $H(x)$ is the Heaviside step function.

The faulting pathway Eq. (2) is commonly considered as twinning pathway in fcc materials [42]. The associated GSFE for $\eta \leqslant 2$ provides, however, sufficient information to analyze three competing deformation modes operating on the same crystallographic slip system (stacking fault, full slip, and twinning) as elaborated in Sec. III C 1.

Special stationary points of $\gamma(\eta \leqslant 2)$ for the previous path are the ISF with associated energy $\gamma_{\text {isf }} \equiv \gamma(1)$ and the extrinsic stacking fault (ESF) with energy $\gamma_{\text {esf }} \equiv \gamma(2)$. Their stacking sequences are indicated in Fig. 1(b). The saddle point encountered between $\gamma(0)$ and $\gamma_{\text {isf }}$ is referred to as the unstable stacking fault (USF) with energy $\gamma_{\text {usf }}$. The unstable 
(a) close-packed planes $(111)_{\mathrm{fcc}}$

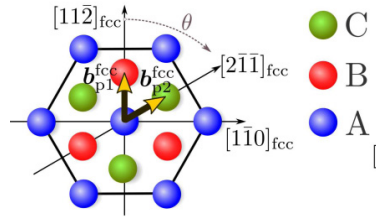

$(0002)_{\text {hcp }}$

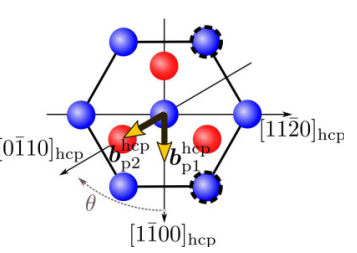

(b) stacking faults on (111) fcc planes
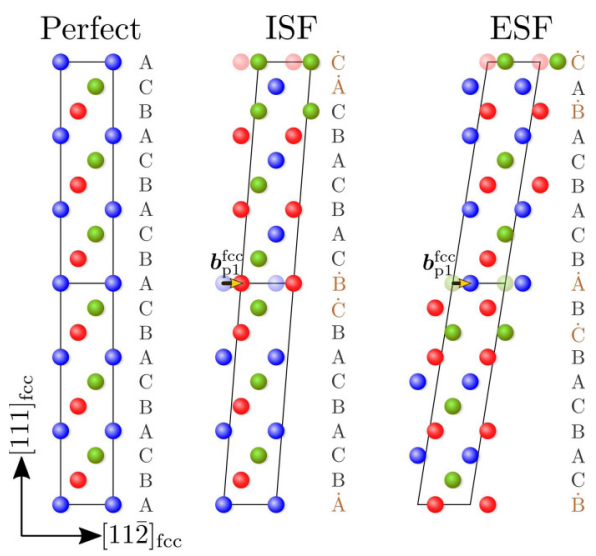

(c) stacking faults on $(0002)_{\text {hcp }}$ planes
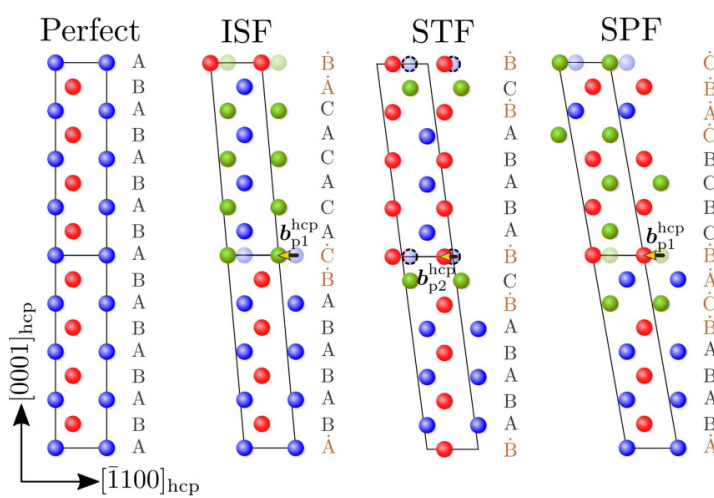

FIG. 1. (a) Schematics of close-packed planes in the fcc and hcp structures with three possible atomic positions A, B, or C, selected crystallographic directions, partial Burgers vectors, and definition of angle $\theta$. Panels (b) and (c) show schematics of extended planar defects imposed by alias shear and modeled by tilted supercells (guided by solid lines). The viewing directions in (b) and (c) are $[1 \overline{1} 0]_{\mathrm{fcc}}$ and $[11 \overline{2} 0]_{\mathrm{hcp}}$, respectively. The stacking sequences of the fault-free and faulted lattices are indicated and refer to one specific $(1 \overline{1} 0)_{\text {fcc }}$ or $(11 \overline{2} 0)_{\text {hcp }}$ plane, wherein labels with a dot $(\dot{\mathrm{A}}$ etc. $)$ in (b) and (c) indicate a nearest neighbor hcp stacking and a nearest neighbor fcc stacking, respectively. $\boldsymbol{b}_{\mathrm{p} 2}^{\text {hcp }}$ tilts the cell out of the figure plane and shifts atoms from an adjacent $(11 \overline{2} 0)_{\text {hcp }}$ plane (indicated by a dashed circle) to the original plane.

twinning fault (UTF) with energy $\gamma_{\text {utf }}$ is the saddle point between $\gamma_{\text {isf }}$ and $\gamma_{\text {esf }}$.

In hcp crystals, we consider the basal $a_{\text {hcp }} / 3[1 \overline{2} 10](0002)_{\text {hcp }}$ slip system where a perfect lattice dislocation can dissociate into two Shockley partials with Burgers vectors $\boldsymbol{b}_{\mathrm{p} 1}^{\mathrm{hcp}}=a_{\mathrm{hcp}} / 3[1 \overline{1} 00]_{\mathrm{hcp}}$ and $\boldsymbol{b}_{\mathrm{p} 2}^{\mathrm{hcp}}=a_{\mathrm{hcp}} / 3[0 \overline{1} 10]_{\mathrm{hcp}} . a_{\mathrm{hcp}}$ the hcp basal lattice parameter and a $(0002)_{\text {hcp }}$ close-packed plane is illustrated in Fig. 1(a).

Unlike the GSFE in the fcc phase, the hcp slip potential energy in a general direction of alias shear between planes $i$ and $i-1$ differs from that between planes $i+1$ and $i$ because the (0002) hcp planes cycle only between two positions (e.g., ... AB ...). To determine the GSFE, we use the convention that positions $A$ and $B$ in the conventional hcp cell are located at the point of origin and at $a_{\mathrm{hcp}} / 3[0 \overline{1} 10]_{\mathrm{hcp}}+$ $c_{\mathrm{hcp}} / 2[0001]_{\mathrm{hcp}}$, respectively, where $c_{\mathrm{hcp}}$ the height lattice parameter. Atoms in stacking planes with odd $i$ assume the A position, and those in planes with even $i$ the B position. We examine the GSFEs for two faulting pathways, which branch at $\eta=1$ and are distinguished by superscripts $\alpha$ and $\beta$, by applying displacement vectors as

$$
\begin{aligned}
\boldsymbol{u}_{i \geqslant 1}^{\alpha}= & {[(y+1) H(y+1)-y H(y)] \delta_{m 1} \boldsymbol{b}_{\mathrm{p} 1}^{\mathrm{hcp}}, } \\
y= & \eta-\frac{i-1}{2}, \quad m=i \bmod 2, \\
\boldsymbol{u}_{i \geqslant 1}^{\beta}= & {[(x+1) H(x+1)-x H(x)] } \\
& \times\left(\delta_{m 1} \boldsymbol{b}_{\mathrm{p} 1}^{\mathrm{hcp}}+\delta_{m 0} \boldsymbol{b}_{\mathrm{p} 2}^{\mathrm{hcp}}\right), \\
\boldsymbol{u}_{i \leqslant 0}^{\alpha, \beta}= & \mathbf{0} .
\end{aligned}
$$

Here, $\delta_{i j}$ is the Kronecker delta and mod the modulus function. Both pathways are illustrated in Fig. 2. The difference between pathways $\alpha$ and $\beta$ is that pathway $\alpha$ shears only every other $(0002)_{\text {hcp }}$ plane (by the same shear vector), whereas pathway $\beta$ shear every plane but the shear vector alternates.

Faulting pathway $\alpha$ is one way to accomplish the hcp to fcc martensitic transformation $[40,43,44]$. In terms of increasing $i$, the stacking sequence of the resulting fcc phase is ... ABC ... [cf. Fig. 1(c)]. A different, though equivalent way of accomplishing the hep to fcc transformation is by shearing every even stacking layer (the B positions) by $\boldsymbol{b}_{\mathrm{p} 2}^{\text {hcp }}$, in which case the resulting fcc phase has the inverse, . . ACB ... stacking sequence. Pathway $\beta$ leads to a twinlike stacking fault configuration [45]. This twinlike stacking fault should be distinguished from crystallographic twin systems in hcp metals and alloys, which most commonly form $\{11 \overline{2} 2\}_{\mathrm{hcp}}$, $\{10 \overline{1} 2\}_{\mathrm{hcp}}$, or $\{10 \overline{1} 1\}_{\mathrm{hcp}}$ twins $[46,47]$. The GSFEs for the faulting pathways Eqs. (3) and $\eta \leqslant 2$ provides sufficient information to analyze four competing deformation modes on $(0002)_{\text {hcp }}$ planes based on leading and partial dislocation nucleation (stacking fault, full slip, twinlike fault, and nano-fcc plate) as elaborated in Sec. III C 2.

The first two stationary points of the GSFE encountered on either pathway are likewise referred to as USF and ISF. On pathway $\alpha$, the energy minimum at $\gamma_{\text {spf }} \equiv \gamma^{\alpha}(2)$ is the stable phase fault (SPF), and the saddle point between $\gamma_{\text {isf }}$ and $\gamma_{\text {spf }}$ is referred to as unstable phase fault (UPF) with energy $\gamma_{\text {upf }}$. On pathway $\beta$, the energy minimum at $\gamma_{\text {stf }} \equiv \gamma^{\beta}(2)$ is the stable twinlike fault (STF), and the saddle point between $\gamma_{\text {isf }}$ and $\gamma_{\text {stf }}$ is referred to as unstable twinlike fault (UTF). The stacking sequences of the stable stacking faults are indicated in Fig. 1(c). The ISF and the STF correspond to the fault $I_{2}$ and the fault $T_{2}$, respectively, in the commonly employed notation of Chetty and Weinert [45]. Note that for convenience UTF 


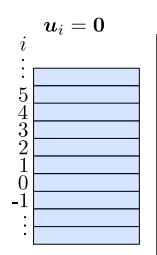

$\eta=0$

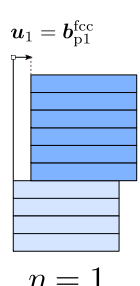

$\eta=1$

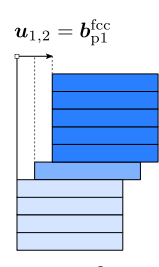

$\eta=2$

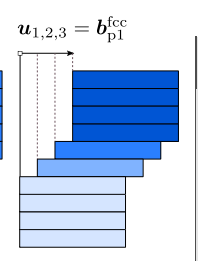

$\eta=3$

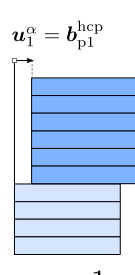

$\eta=1$

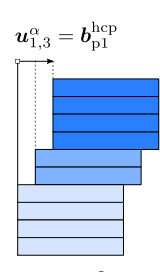

$\eta=2$

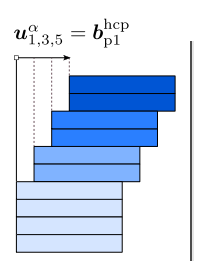

$\eta=3$

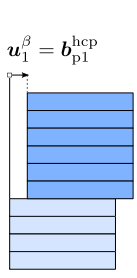

$\eta=1$

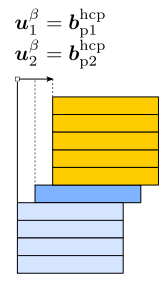

$\eta=2$

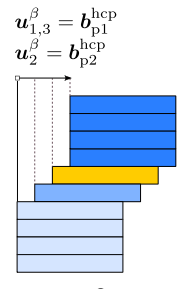

$\eta=3$

FIG. 2. Schematic illustration of the sequential faulting pathways. From left to right: no applied displacements, with relative displacements $\boldsymbol{u}_{i}, \boldsymbol{u}_{i}^{\alpha}$, and $\boldsymbol{u}_{i}^{\beta}$. See the text for definitions and details.

also abbreviates unstable twinning fault in the fcc case, but what UTF stands for is always obvious from context.

\section{B. Determination of the GSFE}

We carried out the calculations of the GSFE for supercells with dimensions $\boldsymbol{e}_{1} \times \boldsymbol{e}_{2} \times \boldsymbol{e}_{3}$ using the tilted supercell methodology [48,49]. In the case of the fcc phase, the cell vectors are $\boldsymbol{e}_{1}=a_{\mathrm{fcc}} / 2[1 \overline{1} 0]_{\mathrm{fcc}}, \boldsymbol{e}_{2}=a_{\mathrm{fcc}} / 2[\overline{1} 01]_{\mathrm{fcc}}$, and $\boldsymbol{e}_{3}=$ $n_{\mathrm{fcc}} a_{\mathrm{fcc}}[111]_{\mathrm{fcc}}$ for vanishing applied alias shear. The GSFE was obtained by gradually displacing $\mathbf{e}_{3}$ in the direction of $\boldsymbol{b}_{\mathrm{p} 1}^{\mathrm{fcc}}$, keeping internal ionic positions fixed, and shifting at $\eta=1$ the cell origin to the neighboring layer as schematically shown in Fig. 1(b). The repeat unit $n_{\mathrm{fcc}}$ was set to 3 after careful tests [nine $(111)_{\mathrm{fcc}}$ layers]. In the case of the hcp phase, the cell vectors are $\boldsymbol{e}_{1}=a_{\mathrm{hcp}} / 3[\overline{1} \overline{1} 20]_{\mathrm{hcp}}, \boldsymbol{e}_{2}=a_{\mathrm{hcp}} / 3[2 \overline{1} \overline{1} 0]_{\mathrm{hcp}}$, and $\boldsymbol{e}_{3}=n_{\mathrm{hcp}} c_{\mathrm{hcp}}[0001]_{\mathrm{hcp}}$ for vanishing applied alias shear. The GSFE was obtained by gradually displacing $\mathbf{e}_{3}$ in the direction of $\boldsymbol{b}_{\mathrm{p} 1}^{\mathrm{hcp}}$ or $\boldsymbol{b}_{\mathrm{p} 2}^{\mathrm{hcp}}$ depending on pathway, keeping internal ionic positions fixed, and shifting at $\eta=1$ the cell origin to a neighboring layer as schematically shown in Fig. 1(c). The repeat unit $n_{\text {hcp }}$ was set to 4 after careful tests [eight (0002) $)_{\text {hcp }}$ layers].

As faulted configurations are created by simple alias shear, structure relaxation is not considered. Going beyond this approximation is possible within the present approach by considering structure relaxation on a mean-field level due to employing the coherent potential approximation (CPA); cf. Sec. IID. As neither stresses nor forces are implemented in the present total energy method (Sec. II D), manual structure relaxation is feasible for one or two free parameters but laborious for many degrees of freedom. Previous DFT investigations for various transition metals and the presently considered faulting pathways showed that structure relaxation typically lowers the GSFE amplitude of unstable stacking faults by typically $10 \%$ but reduces stable stacking fault energies by much less than that value [35,50-53]. We anticipate similar relaxation effects for the presently considered alloys. While we expect that considering structure relaxation does not affect the qualitative behavior of the GSFE curves reported in this paper, quantitatively accurate GSFEs will require full structure relaxation.

\section{Superimposed homogeneous strains}

We imposed two types of homogeneous lattice strains, namely volumetric (hydrostatic) strain and longitudinal strain, to the fault-free lattices to determine how the GSFE varies as a function of state of strain and strain level applied. Strained structures with cell vectors $\boldsymbol{e}_{j}^{\prime}$ (column-major order) are obtained from unstrained ones via

$$
\left[\boldsymbol{e}_{1}^{\prime}, \boldsymbol{e}_{2}^{\prime}, \boldsymbol{e}_{3}^{\prime}\right]=D\left[\boldsymbol{e}_{1}, \boldsymbol{e}_{2}, \boldsymbol{e}_{3}\right]
$$

The diagonal deformation matrices $\boldsymbol{D}=\boldsymbol{D}(\epsilon)$ considered are

$$
\begin{aligned}
\boldsymbol{D}_{\mathrm{v}} & =\operatorname{diag}[1+\epsilon, 1+\epsilon, 1+\epsilon], \\
\boldsymbol{D}_{\mathrm{ss}} & =\operatorname{diag}[1,1,1+\epsilon], \\
\boldsymbol{D}_{\mathrm{vc}} & =\operatorname{diag}\left[(1+\epsilon)^{-1 / 2},(1+\epsilon)^{-1 / 2}, 1+\epsilon\right],
\end{aligned}
$$

in the case of volumetric (v) strain, simple strain (ss), and volume-conserving (vc) strain, respectively. $\epsilon$ is the strain parameter, and positive (negative) values for it are referred to as tensile (compressive) strain. For the two longitudinal strains $\left(\boldsymbol{D}_{\mathrm{ss}}\right.$ and $\left.\boldsymbol{D}_{\mathrm{vc}}\right)$, the strain loading direction is perpendicular to the fault planes, i.e., parallel to $[111]_{\mathrm{fcc}}$ and the $[0001]_{\mathrm{hcp}}$. In the case of simple strain, the respective other two orthogonal directions are fixed, whereas these directions are adjusted to maintain a constant volume for volume-conserving strain.

\section{Total-energy method}

We computed the GSFE via DFT [54] employing the exact muffin-tin orbitals (EMTO) method [55,56] to solve the Kohn-Sham equations [57]. Exchange and correlation were described by the generalized-gradient approximation of the Perdew-Burke-Ernzerhof functional [58]. The scalarrelativistic approximation and the soft-core scheme were used, and the total energy was computed via the full charge-density technique [59]. The electronic structure of substitutionally disordered HEAs was described by the CPA [60,61], with Refs. [59,62] detailing on its implementation in EMTO. The CPA replaces the random alloy potential by a self-consistently determined effective medium, whose properties are as close as possible to those of the configuration average of that alloy. As the configuration average is restricted to a single site of each alloy component embedded in the coherent medium, averages over configurational fluctuations beyond the single site are neglected. The CPA effective medium possesses the symmetries of the underlying lattice.

All spin-polarized DFT calculations were carried out assuming the paramagnetic (PM) state as the magnetic ordering temperatures of the studied HEAs are well below RT. The disordered-local moment (DLM) model was adopted to describe the PM state [63,64]. The DLM model is a first-principles, mean-field type theory for the PM state and describes the electronic structure in the presence of 
static, random orientational spin fluctuations. We solved the DLM model within the random alloy picture analog as described by the CPA $[64,65]$. For instance, the DLM state of $\mathrm{Cr}_{10} \mathrm{Mn}_{30} \mathrm{Fe}_{50} \mathrm{Co}_{10}$ alloy is represented by the pseudooctonary alloy $\mathrm{Cr}_{5}^{\uparrow} \mathrm{Cr}_{5}^{\downarrow} \mathrm{Mn}_{15}^{\uparrow} \mathrm{Mn}_{15}^{\downarrow} \mathrm{Fe}_{25}^{\uparrow} \mathrm{Fe}_{25}^{\downarrow} \mathrm{Co}_{5}^{\uparrow} \mathrm{Co}_{5}^{\downarrow}$, where fractions of atoms with up spins $(\uparrow)$ and down spins $(\downarrow)$ are componentwise equal. Brillouin zone integrations were performed on a $13 \times 25 \times 3$ and a $12 \times 24 \times 3 k$-points mesh for hcp and fcc GSFE calculations, respectively, determined after careful testing.

We carried out an assessment for various special points on the considered faulting pathways for fcc $\mathrm{Cu}$ and hcp $\mathrm{Mg}$. The results detailed in Appendix A show that the present total energy method gives a precise description of the close-packed plane GSFEs in fcc and hep systems.

The employed theoretical equilibrium lattice parameters for the HEAs considered in this study equal those previously determined by Li et al. [66] and were discussed therein. For the sake of a self-contained presentation, we tabulate them in Appendix B.

\section{RESULTS AND DISCUSSION}

\section{A. Generalized stacking fault energies at equilibrium}

Figure 3 shows the calculated GSFE curves up to a total displacement of $\eta=2$ for the five studied polymorphic HEAs in their fcc and hep phases. In the fcc phase, the five alloys have similar $\gamma_{\text {usf }}^{\mathrm{fcc}}$, while $\gamma_{\text {isf }}^{\mathrm{fcc}}, \gamma_{\mathrm{esf}}^{\mathrm{fcc}}$, and $\gamma_{\text {utf }}^{\text {fcc }}$ differ strongly. The latter three fault energies are the highest for $\mathrm{Cr}_{25} \mathrm{Fe}_{25} \mathrm{Co}_{25} \mathrm{Ni}_{25}$ and decrease in the sequence $\mathrm{Cr}_{20} \mathrm{Mn}_{20} \mathrm{Fe}_{30} \mathrm{Co}_{20} \mathrm{Ni}_{10}, \mathrm{Cr}_{20} \mathrm{Mn}_{20} \mathrm{Fe}_{34} \mathrm{Co}_{20} \mathrm{Ni}_{6}$, and $\mathrm{Cr}_{10} \mathrm{Mn}_{30} \mathrm{Fe}_{50} \mathrm{Co}_{10}$, i.e., with decreasing net valence electron count (VEC). All the $\gamma_{\text {isf }}^{\text {fcc }}$ and $\gamma_{\text {esf }}^{\mathrm{fcc}}$ values are negative with $\gamma_{\text {isf }}^{\mathrm{fcc}}$ being slightly lower in energy than $\gamma_{\mathrm{esf}}^{\mathrm{fcc}}$. Negative $\gamma_{\text {isf }}^{\text {fcc }}$ values for $\mathrm{Cr}_{25} \mathrm{Fe}_{25} \mathrm{Co}_{25} \mathrm{Ni}_{25}$ and $\mathrm{Cr}_{20} \mathrm{Mn}_{20} \mathrm{Fe}_{20} \mathrm{Co}_{20} \mathrm{Ni}_{20}$ were previously reported [67].

Often, direct connections between the magnitude of $\gamma_{\text {isf }}^{\mathrm{fcc}}$ and the hcp versus fcc phase stability are drawn $[11,49]$ based on

$$
\begin{aligned}
\gamma_{\mathrm{isf}}^{\mathrm{fcc}} A & \approx 2\left(E_{\mathrm{hcp}}-E_{\mathrm{fcc}}\right) \equiv 2 \Delta E_{\mathrm{hpp}-\mathrm{fcc}}, \\
& \gtrsim 2\left(E_{\mathrm{hcp}}^{*}-E_{\mathrm{fcc}}\right) \equiv 2 \Delta E_{\mathrm{hcp}-\mathrm{fcc}}^{*} .
\end{aligned}
$$

The first approximation results from the axial nearest neighbor Ising model for the fcc phase [68] and considers differences in stacking sequences. The second line differs from the first in that $E_{\mathrm{hcp}}^{*}$ is the energy of the relaxed hcp phase. Thus, the negative $\gamma_{\text {isf }}^{\mathrm{fcc}} \mathrm{s}$ in these HEAs suggest that the hcp phase is more stable than the fcc phase at zero temperature, and $\mathrm{Cr}_{10} \mathrm{Mn}_{30} \mathrm{Fe}_{50} \mathrm{Co}_{10}$ is predicted to be the most stable in the hop phase. By explicit total-energy calculations, we found $\Delta E_{\text {hcp-fcc }}^{*}<0$ and verified that the correlation in Eq. (5b) holds. That is, the hcp phase is the theoretical ground state phase for the considered alloys, while the fcc phase is metastable. These findings are consistent with the available experimental observations for $\mathrm{Cr}_{20} \mathrm{Mn}_{20} \mathrm{Fe}_{20} \mathrm{Co}_{20} \mathrm{Ni}_{20}$, $\mathrm{Cr}_{20} \mathrm{Mn}_{20} \mathrm{Fe}_{34} \mathrm{Co}_{20} \mathrm{Ni}_{6}$, and $\mathrm{Cr}_{10} \mathrm{Mn}_{30} \mathrm{Fe}_{50} \mathrm{Co}_{10}$, which revealed the metastability of their fcc phase at RT $[5,11,12,14]$.

The total energy difference, or $\gamma_{\text {isf }}^{\text {fcc }}$ following Eq. (5b), indicates the chemical driving force for the martensitic fcc
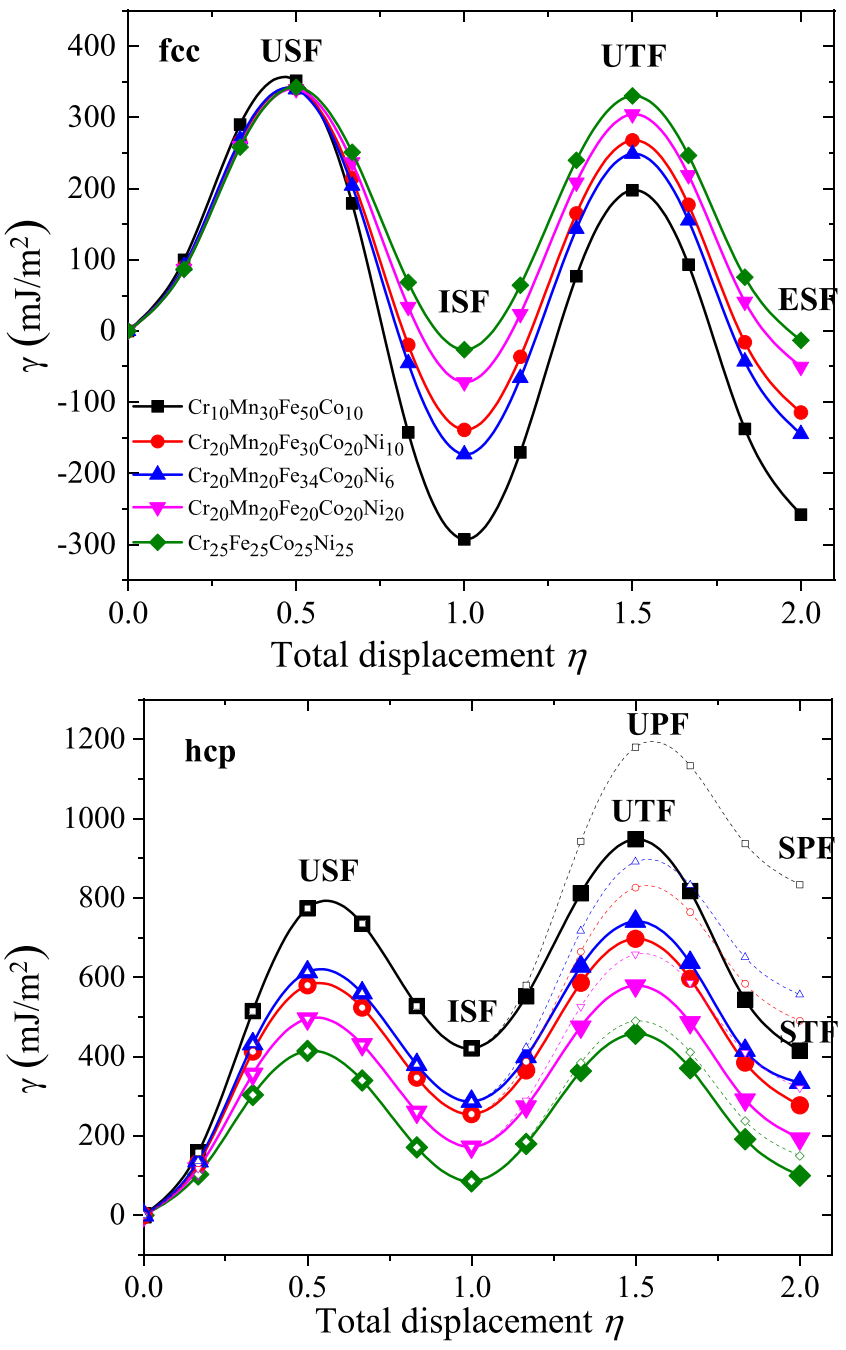

FIG. 3. The GSFEs $\gamma(\eta)$ for the faulting pathways in the fcc and hcp phases and the five considered HEAs. The GSFE curves for the pathways $\alpha$ and $\beta$ in the hcp phases after branching at $\eta=1$ are distinguished by dashed and solid lines, respectively. Special stationary points are indicated.

to hep phase transformation. Thus, $\mathrm{Cr}_{10} \mathrm{Mn}_{30} \mathrm{Fe}_{50} \mathrm{Co}_{10}$ and $\mathrm{Cr}_{20} \mathrm{Mn}_{20} \mathrm{Fe}_{34} \mathrm{Co}_{20} \mathrm{Ni}_{6}$ are predicted to have the largest hcp formation tendency. A dual phase microstructure was indeed found experimentally for both alloys prior to mechanical loading $[5,11]$. The experimental phase fractions, determined under similar processing conditions (high-temperature water quenching in the homogenized state), correlate well with their ranking according to $\gamma_{\text {isf }}^{\mathrm{fcc}}$. The fcc to hcp allotropic transformation in $\mathrm{Cr}_{20} \mathrm{Mn}_{20} \mathrm{Fe}_{20} \mathrm{Co}_{20} \mathrm{Ni}_{20}$ did not occur under ordinary processing conditions $[69,70]$ but requires mechanical stimulation to overcome the transformation barrier $[12,14]$, which is again consistent with a low chemical driving force.

A simple and direct means of assessing whether the spin polarization of the electronic structure gives an important contribution to the GSFE amplitude is achieved by comparing to results of non-spin-polarized electronic structure calculations (nonmagnetic state). To this end, we performed additional non-spin-polarized DFT calculations using the equilibrium 
lattice parameters from Table II to isolate the magnetic effect and avoid possible interference from volumetric contributions. Upon invoking spin polarization (PM state), we found that $\gamma_{\text {usf }}^{\text {fcc }}$ decrease $\left(10-30 \mathrm{~mJ} / \mathrm{m}^{2}\right)$ and $\gamma_{\text {utf }}^{\text {fcc }}$ increase $\left(<20 \mathrm{~mJ} / \mathrm{m}^{2}\right)$ slightly across the alloys, whereas $\gamma_{\text {isf }}^{\text {fcc }}$ and $\gamma_{\text {esf }}^{\text {fcc }}$ increase by $50-60 \mathrm{~mJ} / \mathrm{m}^{2}$ and $45-70 \mathrm{~mJ} / \mathrm{m}^{2}$, respectively, across the alloys. These results suggest that the spin polarization of the electronic structure gives an important contribution to the GSFE amplitude in the present alloys. In all alloy cases, Fe sites were found to carry the largest local magnetic moments in the PM state, with smaller induced magnetic moments on $\mathrm{Mn}$ and Co sites and practically vanishing local magnetic moment on $\mathrm{Ni}$ and $\mathrm{Cr}$ sites. No obvious correlation between above described changes in GSFE amplitude and the fraction of spin-polarized chemical species could be detected.

Turning to the hcp phase, the planar fault energies $\gamma_{\text {isf }}^{\text {hcp }}$, $\gamma_{\text {usf }}^{\text {hcp }}, \gamma_{\text {utf }}^{\text {hcp }}, \gamma_{\text {stf }}^{\text {hcp }}, \gamma_{\text {upf }}^{\text {hcp }}$, and $\gamma_{\mathrm{spf}}^{\text {hcp }}$ are positive throughout. The $\gamma_{\text {isf }}^{\text {hcp }}$ and $\gamma_{\text {stf }}^{\text {hcp }}$ values are very similar, although these faults have different stacking sequences. $\gamma_{\mathrm{upf}}^{\mathrm{hcp}}$ and $\gamma_{\mathrm{spf}}^{\mathrm{hcp}}$ on pathway $\beta$ are larger than $\gamma_{\text {utf }}^{\text {hcp }}$ and $\gamma_{\text {sff }}^{\text {hcp }}$ on pathway $\alpha$, which is consistent with short-ranged interactions between $(0002)_{\text {hcp }}$ planes as explained below. The six planar fault energies are the smallest for $\mathrm{Cr}_{25} \mathrm{Fe}_{25} \mathrm{Co}_{25} \mathrm{Ni}_{25}$ and increase with decreasing VEC from $\mathrm{Cr}_{20} \mathrm{Mn}_{20} \mathrm{Fe}_{20} \mathrm{Co}_{20} \mathrm{Ni}_{20}, \mathrm{Cr}_{20} \mathrm{Mn}_{20} \mathrm{Fe}_{30} \mathrm{Co}_{20} \mathrm{Ni}_{10}$, $\mathrm{Cr}_{20} \mathrm{Mn}_{20} \mathrm{Fe}_{34} \mathrm{Co}_{20} \mathrm{Ni}_{6}$, to $\mathrm{Cr}_{10} \mathrm{Mn}_{30} \mathrm{Fe}_{50} \mathrm{Co}_{10}$. The positiveness of the fault energies confirms the stability of the hcp phase at zero temperature. The $\gamma_{\text {uff }}^{\text {hcp }}$ are larger than the $\gamma_{\text {usf }}^{\text {hcp }}$ for all investigated HEAs, which is opposite to the fcc phase.

\section{B. Generalized stacking fault energies under applied strain}

We investigated the GSFEs under superimposed strain for two HEAs, $\mathrm{Cr}_{10} \mathrm{Mn}_{30} \mathrm{Fe}_{50} \mathrm{Co}_{10}$ and $\mathrm{Cr}_{20} \mathrm{Mn}_{20} \mathrm{Fe}_{20} \mathrm{Co}_{20} \mathrm{Ni}_{20}$. They were selected because both show deformation twinning (cf. Sec. III C 1). The calculated fault energies of these two HEAs under volumetric strain, volume-conserving strain, and simple strain are shown in Figs. 4 and 5. Volumetric strain deformations are plotted as a function of the volumetric strain $\Delta V / V_{0}=(1+\epsilon)^{3}-1, \Delta V=V-V_{0}$, where $V=V(\epsilon)$ is the volume and $V_{0}=V(0)$ is the equilibrium volume.

For fcc $\mathrm{Cr}_{20} \mathrm{Mn}_{20} \mathrm{Fe}_{20} \mathrm{Co}_{20} \mathrm{Ni}_{20}$ shown in Fig. 4(a), both $\gamma_{\text {isf }}^{\text {fcc }}$ and $\gamma_{\text {esf }}^{\text {fcc }}$ steadily and nonlinearly increase with increasing strain under all three strain conditions. The nonlinearity is the most pronounced for simple strain. $\gamma_{\text {isf }}^{\mathrm{fcc}}$ and $\gamma_{\mathrm{esf}}^{\mathrm{fcc}}$ change sign at strains $\epsilon$ approximately equal to $7 \%, 10 \%$, and $5 \%$ under volumetric strain, volume conserving strain, and simple strain, respectively. In addition, the values of $\gamma_{\mathrm{esf}}^{\mathrm{fcc}}$ remain slightly larger than those of $\gamma_{\text {isf }}^{\text {fcc }}$, but their difference becomes smaller with increasing strain.

The decreasing trend of $\gamma_{\text {usf }}^{\text {fcc }}$ with decreasing compressive strain and increasing tensile strain is similar for the three states of strain, which is also found for $\gamma_{\text {utf }}^{\mathrm{fcc}}$ under volumetric strain. In contrast, $\gamma_{\text {utf }}^{\text {fcc }}$ exhibits a pronounced nonlinear, nearly parabolic dependence under longitudinal strain with maximum value at approximately $5 \%$ tensile strain (volume-conserving strain) and near zero strain (simple strain). Noticeable is also the increasingly larger difference between $\gamma_{\text {utf }}^{\text {fcc }}$ and $\gamma_{\text {usf }}^{\text {fcc }}$ with increasing compressive strain, which is not seen under tensile deformation. (a) fcc phase
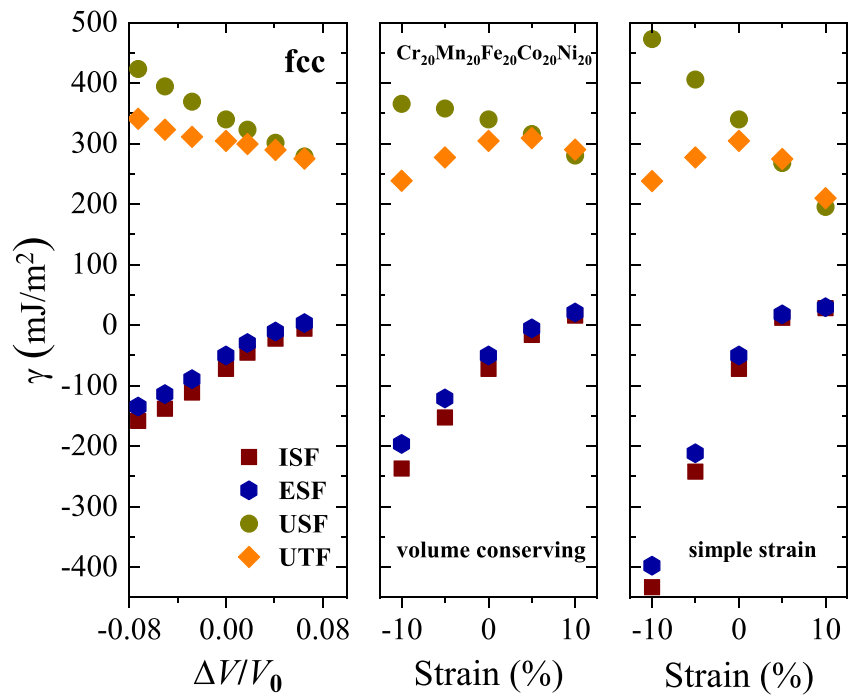

(b) hcp phase
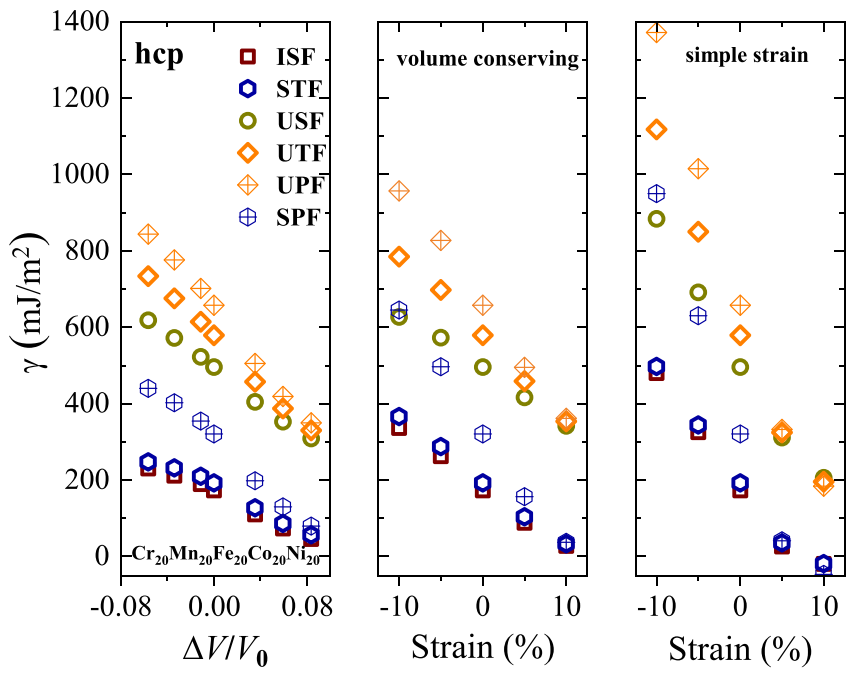

FIG. 4. The GSFE of stationary points on the faulting pathways as a function of applied strain for three states of superimposed strain in fcc and hcp $\mathrm{Cr}_{20} \mathrm{Mn}_{20} \mathrm{Fe}_{20} \mathrm{Co}_{20} \mathrm{Ni}_{20}$.

For the hcp phase shown in Fig. 4(b), it is evident that all six fault energies decrease with decreasing compressive strain and increasing tensile strain in all three states of strain. Simple strain has the most pronounced influence on the fault energies, which is similar to the fcc phase.

The trends for $\mathrm{Cr}_{10} \mathrm{Mn}_{30} \mathrm{Fe}_{50} \mathrm{Co}_{10}$ shown in Fig. 5 are qualitatively similar to those for $\mathrm{Cr}_{20} \mathrm{Mn}_{20} \mathrm{Fe}_{20} \mathrm{Co}_{20} \mathrm{Ni}_{20}$. Two noticeable quantitative differences are that, first, $\gamma_{\text {usf }}^{\text {hcp }}$ and $\gamma_{\text {utf }}^{\text {hcp }}$ diverge more rapidly under compressive strains and, second, $\gamma_{\text {isf }}^{\text {hcp }}$ and $\gamma_{\text {esf }}^{\text {hcp }} / \gamma_{\text {sff }}^{\text {hcp }}$ change more strongly as a function of the strain parameter $\epsilon$.

The data provided in Figs. 4 and 5 confirms via Eq. (5b) the expected increase of the hcp phase stability in $\mathrm{Cr}_{10} \mathrm{Mn}_{30} \mathrm{Fe}_{50} \mathrm{Co}_{10}$ and $\mathrm{Cr}_{20} \mathrm{Mn}_{20} \mathrm{Fe}_{20} \mathrm{Co}_{20} \mathrm{Ni}_{20}$ with pressure (negative volumetric strain). One may also estimate the effect of temperature-induced lattice expansion on the special stationary points (positive volumetric strain), e.g., a $3 \%$ 
(a) fcc phase
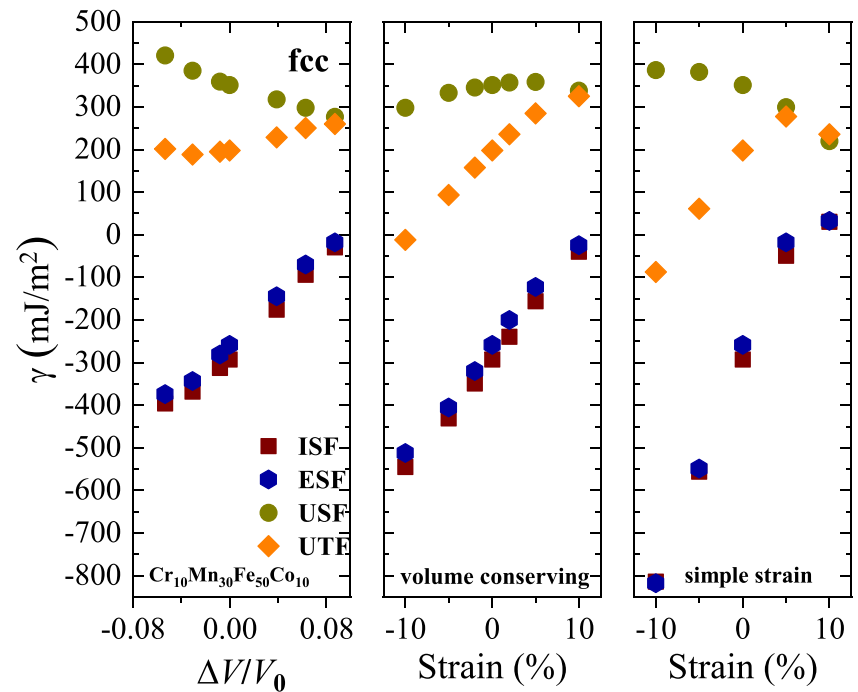

(b) hcp phase
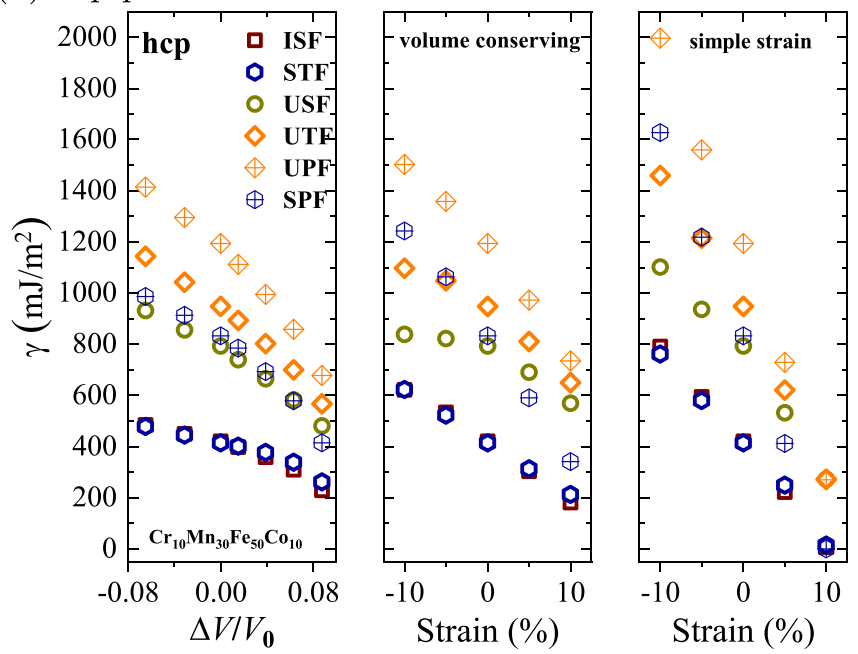

FIG. 5. The GSFE of stationary points on the faulting pathways as a function of applied strain for three states of superimposed strain in fcc and hep $\mathrm{Cr}_{10} \mathrm{Mn}_{30} \mathrm{Fe}_{50} \mathrm{Co}_{10}$.

volume increase is associated with the effect of typically a few hundred degrees Celsius. Accordingly, the effect of lattice expansion may lead to both decreasing and increasing planar fault energies. Furthermore, the shown strain dependencies of stationary points implies that the GSFE surfaces are the least corrugated at the largest superimposed tensile strains, i.e., when the interplanar distance between fcc or hcp close-packed planes is the largest. This plausibly suggests that under tensile strains the electron density across the slip plane is the least perturbed by alias shear (presumably because of the enlarged interstitial region), which is consistent with short-ranged interlayer interactions (cf. Sec. III D).

\section{Deformation modes}

Dislocation slip by complete or extended dislocations, martensitic transformation, and deformation twinning are competing plastic deformation modes in many metals and alloys. Activated deformation twinning, for instance, can benefit strain hardening rate, and often plays an important role in improving the macroscopic mechanical properties of materials.

In the following two Secs. III C 1 and III C 2, we examine competing plastic deformation modes in the considered HEAs from a microscopic point of view. The plastic deformation modes operate on the same slip system and involve dislocation nucleation and glide of leading and trailing Shockley partials on $\{111\}_{\mathrm{fcc}}$ or $(0002)_{\mathrm{hcp}}$ close-packed planes. We evaluate the competition between the modes using data from the determined GSFE curves. In Sec. III C 3 we contrast the theoretical outcome with available experimental observations.

\section{Deformation modes on $\{111\}_{f c c}$ planes}

Assume the presence of an ISF created by a leading partial dislocation with Burger vector $\boldsymbol{b}_{\mathrm{p} 1}^{\mathrm{fcc}}$. The competition between full slip (SL) and twinning (TW) deformation modes is associated with the nucleation and glide of a second, leading or trailing partial $[30,71,72]$. An emission of a trailing partial with Burgers vector $\boldsymbol{b}_{\mathrm{p} 2}^{\mathrm{fcc}}$ on the original slip plane removes the stacking fault (SL), whereas emission of $\boldsymbol{b}_{\mathrm{p} 1}^{\mathrm{fcc}}$ on an adjacent plane leads to formation of a two-layer microtwin (TW). SL and TW are correlated modes as both require a pre-existing ISF. A third deformation mode, stacking fault (SF), is the uncorrelated emission of a leading partial $\boldsymbol{b}_{\mathrm{p} 1}^{\mathrm{fc}}$ forming an isolated ISF (the existing and newly formed stacking faults are assumed to be decoupled).

The athermal intrinsic energy barriers (IEBs) associated with SF, SL, and TW modes are $\gamma_{\text {usf }}^{\mathrm{fcc}}, \gamma_{\mathrm{usf}}^{\mathrm{fcc}}-\gamma_{\mathrm{isf}}^{\mathrm{fcc}}$, and $\gamma_{\mathrm{utf}}^{\mathrm{fcc}}-$ $\gamma_{\text {isf }}^{\text {fcc }}$, respectively $[30,71,73]$. The competition between these modes on a particular slip plane can be evaluated by comparing the projected components of an applied shear stress necessary to initiate slip in the respective slip directions, i.e., the critical resolved nucleation stresses. Equivalently, one can compare the effective energy barriers (EEBs) for a given direction of applied in-plane shear defined by normalizing the bare IEBs as $[27,74]$

$$
\begin{aligned}
& \bar{\gamma}_{\mathrm{sf}}(\theta)=\frac{\gamma_{\mathrm{uf}}^{\mathrm{fcc}}}{\cos \theta}, \\
& \bar{\gamma}_{\mathrm{tw}}(\theta)=\frac{\gamma_{\mathrm{uff}}^{\mathrm{fcc}}-\gamma_{\mathrm{isf}}^{\mathrm{fcc}}}{\cos \theta}, \\
& \bar{\gamma}_{\mathrm{sl}}(\theta)=\frac{\gamma_{\mathrm{usf}}^{\mathrm{fcc}}-\gamma_{\mathrm{isf}}^{\mathrm{fcc}}}{\cos \left(\theta-60^{\circ}\right)} .
\end{aligned}
$$

Assuming specifically the (111) fcc glide plane, the angle $\theta$ measures the direction of applied shear clockwise around the $[111]_{\mathrm{fcc}}$ axis, where $0^{\circ}$ is in the positive $[11 \overline{2}]_{\mathrm{fcc}}$ direction and $60^{\circ}$ in the positive $[2 \overline{1} \overline{1}]_{\text {fcc }}$ direction [cf. Fig. 1(a)]. The interval $0^{\circ} \leqslant \theta \leqslant 60^{\circ}$ covers all nonequivalent stress directions due to crystal symmetry. The deformation mode fraction $f$ quantifies how frequently a deformation mode occurs (i.e., the normalized $\theta$ domain in which a deformation mode has the lowest EEB).

Figure 6(a) shows the three EEBs from Eq. (6) for fcc $\mathrm{Cr}_{25} \mathrm{Fe}_{25} \mathrm{Co}_{25} \mathrm{Ni}_{25}$ and $\mathrm{Cr}_{10} \mathrm{Mn}_{30} \mathrm{Fe}_{50} \mathrm{Co}_{10}$ determined from the GSFEs without superimposed strain. We note that qualitatively similar behavior was found for the three other considered alloys (not shown). The SF and SL modes are the predicted activated deformation modes as indicated by 
(a) fcc phase
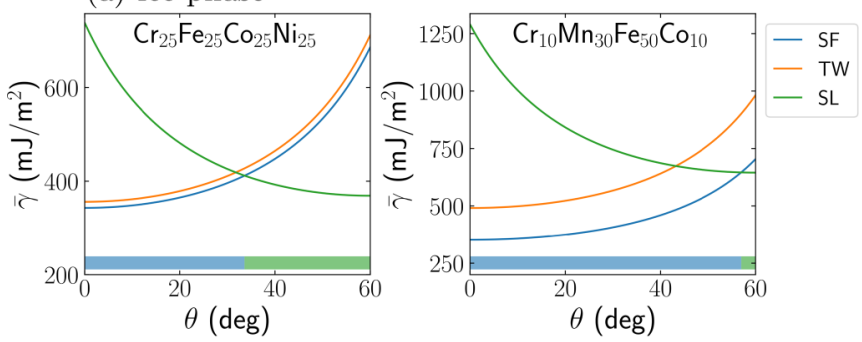

(b) hcp phase
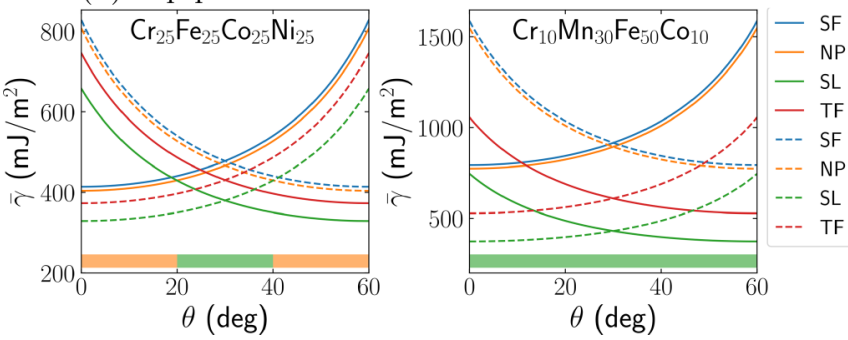

FIG. 6. The EEBs of $\mathrm{Cr}_{25} \mathrm{Fe}_{25} \mathrm{Co}_{25} \mathrm{Ni}_{25}$ and $\mathrm{Cr}_{10} \mathrm{Mn}_{30} \mathrm{Fe}_{50} \mathrm{Co}_{10}$ in (a) the fcc phase and (b) the hcp phase determined from the GSFEs without superimposed strain. Solid and dashed lines in (b) refer to $\bar{\gamma}^{\mathrm{I}}$ and $\bar{\gamma}^{\text {II }}$, respectively. The horizontal bar at the bottom of each panel indicates which deformation mode is activated as a function of $\theta$ (the total width of a mode normalized by $60^{\circ}$ equals its deformation mode fraction).

the colored bars in Fig. 6(a). The TW mode does not occur, as SF and TW modes have the same $\theta$ dependence but SF has the lower IEB $\left(\gamma_{\mathrm{usf}}^{\mathrm{fcc}}<\gamma_{\mathrm{utf}}^{\mathrm{fcc}}-\gamma_{\mathrm{isf}}^{\mathrm{fcc}}\right)$. A transition point defined by $\bar{\gamma}_{\mathrm{sf}}\left(\theta_{c}\right)=\bar{\gamma}_{\mathrm{sl}}\left(\theta_{c}\right)\left(\theta_{c} \in\left[0^{\circ}, 60^{\circ}\right]\right)$ divides the $\theta$ interval into a domain where SF is preferred $\left(\bar{\gamma}_{\mathrm{sf}}<\bar{\gamma}_{\mathrm{sl}}\right)$ and a domain where SL is preferred $\left(\bar{\gamma}_{\mathrm{sf}}>\bar{\gamma}_{\mathrm{sl}}\right)$. SF is the dominantly activated deformation mode in all considered alloys $\left(\theta_{c}>30^{\circ}, f_{\text {sf }}>0.5\right)$ and SL the secondary one. Their relative frequency varies across the alloys: $f_{\mathrm{sf}}$ is the smallest for $\mathrm{Cr}_{25} \mathrm{Fe}_{25} \mathrm{Co}_{25} \mathrm{Ni}_{25}$ (0.56), followed by $\mathrm{Cr}_{20} \mathrm{Mn}_{20} \mathrm{Fe}_{20} \mathrm{Co}_{20} \mathrm{Ni}_{20}$ (0.66), $\mathrm{Cr}_{20} \mathrm{Mn}_{20} \mathrm{Fe}_{30} \mathrm{Co}_{20} \mathrm{Ni}_{10}$ (0.77), $\mathrm{Cr}_{20} \mathrm{Mn}_{20} \mathrm{Fe}_{34} \mathrm{Co}_{20} \mathrm{Ni}_{6}$ (0.82), and $\mathrm{Cr}_{10} \mathrm{Mn}_{30} \mathrm{Fe}_{50} \mathrm{Co}_{10}(0.95)$. The order is vice versa for $f_{\mathrm{sl}}=1-f_{\mathrm{sf}}$.

These findings suggest that many uncorrelated ISFs occur in the fcc phase during plastic deformation, particularly during the initial stage and most frequently for $\mathrm{Cr}_{10} \mathrm{Mn}_{30} \mathrm{Fe}_{50} \mathrm{Co}_{10}$ and $\mathrm{Cr}_{20} \mathrm{Mn}_{20} \mathrm{Fe}_{34} \mathrm{Co}_{20} \mathrm{Ni}_{6}$. Besides, glide of complete $a_{\mathrm{fcc}} / 2\langle 1 \overline{1} 0\rangle$ dislocations occurs. Formation of uncorrelated ISFs lowers the Gibbs energy of the fcc phase in these alloys, while their mutual interaction due to increased stacking fault density may affect the energy dissipation process. ISFs can act as nuclei for the martensitic transformation to the stable hcp phase. Microscopically, a thin hcp martensite plate can form by correlated nucleation of a leading partial $\boldsymbol{b}_{\mathrm{p} 1}^{\mathrm{fcc}}$ on the next but one plane containing the original ISF [75]. That is, an fcc lattice with ISF has the stacking of $\ldots$. СABCं $\dot{B} C A B C \ldots$ and after emission of $\boldsymbol{b}_{\mathrm{p} 1}^{\mathrm{fcc}}$ (on the underlined plane) the stacking becomes ... САВ $\dot{C} \dot{B} \dot{C} \dot{B} C A B C \ldots$, doubling the number of close-packed layers with nearest neighbor hcp stacking (indicated by a dot). The IEB for the correlated nucleation of a leading partial $\boldsymbol{b}_{\mathrm{p} 1}^{\mathrm{fcc}}$ on the next but one plane containing the original ISF is expected to be rather (a) fcc phase
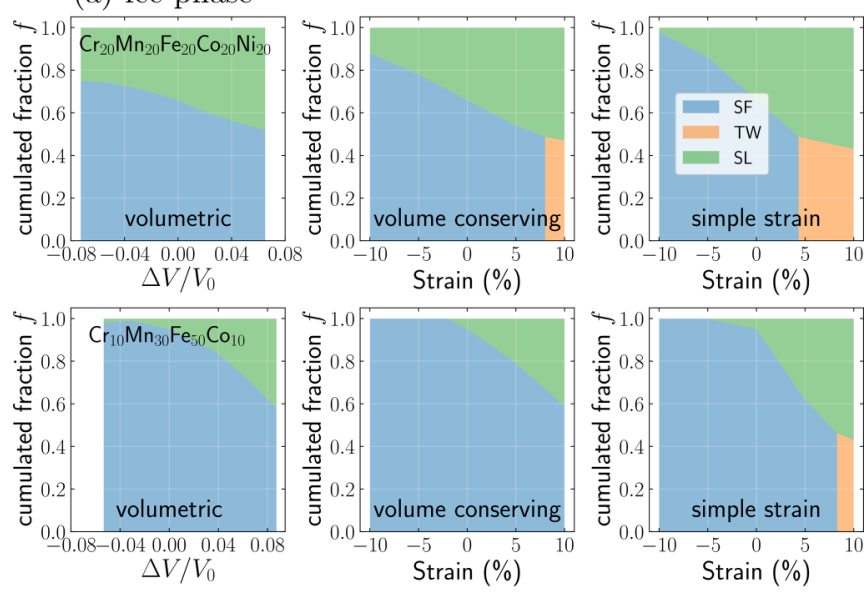

(b) hcp phase
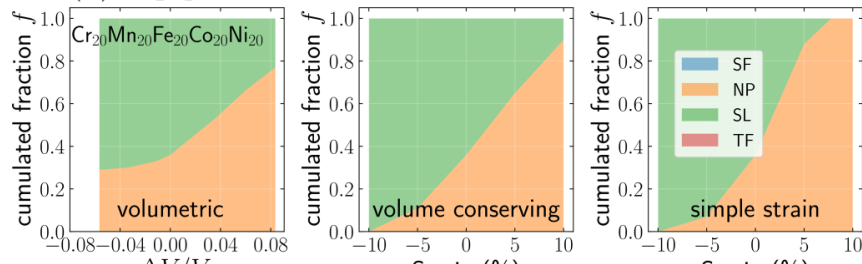

$\Delta V / V_{0}$
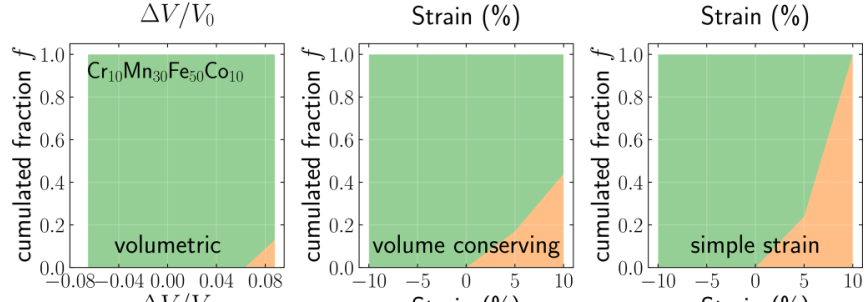

$\Delta V / V_{0}$

FIG. 7. Cumulated deformation mode fractions in (a) the fcc phase and (b) the hcp phase of $\mathrm{Cr}_{20} \mathrm{Mn}_{20} \mathrm{Fe}_{20} \mathrm{Co}_{20} \mathrm{Ni}_{20}$ and $\mathrm{Cr}_{10} \mathrm{Mn}_{30} \mathrm{Fe}_{50} \mathrm{Co}_{10}$ as a function of strain for three states of superimposed strain. Note that not every deformation mode is activated.

similar to that of the SF mode, due to short-ranged interactions between close-packed layers (cf. discussion in Sec. III D and related results for the hcp phase, Sec. III C 2). Growth of a hcp plate can proceed by repeated nucleation of $\boldsymbol{b}_{\mathrm{p} 1}^{\mathrm{fcc}}$ partials on every other $(111)_{\text {fcc }}$ plane, where the fcc matrix and hcp plate assume the Shoji-Nishiyama (SN) orientation relationship of $(0002)_{\text {hcp }} \|(111)_{\text {fcc }}$ and $[11 \overline{2} 0]_{\text {hcp }} \|[1 \overline{1} 0]_{\text {fcc }}$.

Turning to the effect of superimposed strain on the competition between SF, SL, and TW modes, Fig. 7(a) shows the predicted deformation mode fractions $f_{\mathrm{sf}}, f_{\mathrm{sl}}$, and $f_{\mathrm{tw}}$ in fcc $\mathrm{Cr}_{20} \mathrm{Mn}_{20} \mathrm{Fe}_{20} \mathrm{Co}_{20} \mathrm{Ni}_{20}$ and $\mathrm{Cr}_{10} \mathrm{Mn}_{30} \mathrm{Fe}_{50} \mathrm{Co}_{10}$ as a function of state of strain and strain level applied. SF remains the dominant deformation mode in the case of compressive strains and for both alloys, in which $f_{\text {sf }}$ typically increases with the magnitude of compressive strain. The TW mode replaces SF for tensile simple strain in both alloys, as well as in $\mathrm{Cr}_{20} \mathrm{Mn}_{20} \mathrm{Fe}_{20} \mathrm{Co}_{20} \mathrm{Ni}_{20}$ under tensile volume-conserving longitudinal strain. The reason for the transition from SF to TW is that the nucleation barrier for SF decreases to below that for TW as the strain level increases. As SF and TW are mutually exclusive modes in the theory of athermal EEBs, their deformation mode fractions change abruptly as shown in Fig. 7(a). 
Note that in drawing Fig. 7(a) we estimated the strain at which this transition occurs based on interpolated GSFEs. Moreover, $f_{\mathrm{sl}}$ increases with tensile strain due to the fact that the IEBs for SF, SL, and TW approximate each other. In both $\mathrm{Cr}_{20} \mathrm{Mn}_{20} \mathrm{Fe}_{20} \mathrm{Co}_{20} \mathrm{Ni}_{20}$ and $\mathrm{Cr}_{10} \mathrm{Mn}_{30} \mathrm{Fe}_{50} \mathrm{Co}_{10} f_{\text {sl }}$ exceeds 0.5 at the largest considered tensile simple strains, suggesting that SL becomes the dominating deformation mode under this condition.

\section{Deformation modes on $(0002)_{h c p}$ planes}

The theory of competing deformation modes on (0002) hcp $_{\text {h }}$ planes as described by EEBs can be formulated largely analogously to the fcc phase. This is due to crystallographic similarity between $\{111\}_{\mathrm{fcc}}$ and $(0002)_{\mathrm{hcp}}$ close-packed planes, which implies, for instance, that all nonequivalent in-plane shear stress directions are confined to a $\theta$ interval of $60^{\circ}$. Readers are, however, reminded that in the case of the hcp lattice the potential energy change for alias shearing an A plane over a B plane in a general shear direction differs from that of shearing a B plane over an A plane in the same direction (similar considerations apply to when the hcp stacking sequence is assumed to be ... AC . . or ... BC ...). This is in contrast to the fcc lattice, where alias shearing an A plane over a $\mathrm{C}$ plane, a $\mathrm{B}$ plane over an A plane, or a $\mathrm{C}$ plane over a $\mathrm{B}$ plane yields the same potential energy surface for the same direction of alias shear. Readers may convince themselves of this difference with the help of Fig. 1(a), e.g., by comparing the positions resulting from translating $\mathrm{A}, \mathrm{B}$, or $\mathrm{C}$ positions in the direction of $\boldsymbol{b}_{\mathrm{p} 1}^{\mathrm{fcc}}$ or $\boldsymbol{b}_{\mathrm{p} 1}^{\mathrm{hcp}}$. As elaborated below, a consequence of the hcp stacking is that there is an equivalent faulting pathway to each of the considered sequential faulting pathways. There are thus two EEBs for each considered deformation mode [76].

First note that the currently considered faulting pathways [Eq. (3)] translate between the three possible atomic positions in a $(0002)_{\text {hep }}$ plane by displacement vectors of Shockley type. Displacements that would result in two or more consecutive stacking planes occupying the same position (e.g., B followed by $B$ ) increase the potential energy strongly and are not permitted. Alias shearing is thus always into the unoccupied position, e.g., shearing an A plane over a B plane into the $\mathrm{C}$ position. The displacement vectors of Shockley type to accomplish this belong to one out of two disjoint sets of displacement vectors. These sets are referred to as I and II in the following, where $\mathrm{I}=\left\{\boldsymbol{b}_{\mathrm{p} 1}^{\mathrm{hcp}}, a_{\mathrm{hcp}} / 3[\overline{1} 010]_{\mathrm{hcp}}, a_{\mathrm{hcp}} / 3[01 \overline{1} 0]_{\mathrm{hcp}}\right\}$ and II $=\left\{\boldsymbol{b}_{\mathrm{p} 2}^{\mathrm{hcp}}, a_{\mathrm{hcp}} / 3[\overline{1} 100]_{\mathrm{hcp}}, a_{\mathrm{hcp}} / 3[10 \overline{1} 0]_{\mathrm{hcp}}\right\}$.

Due to crystal symmetry of the hcp structure, there are two different routes to create the same planar stacking fault by sequential faulting. Both routes are equivalent and merely involve different directions of shear depending on stacking plane sheared. Consider an example: An ISF can be formed by shearing an A plane over a B plane by $\boldsymbol{b}_{\mathrm{p} 1}^{\text {hcp }}$ or, equivalently, by shearing a B plane over an A plane by $\boldsymbol{b}_{\mathrm{p} 2}^{\text {hcp }}$. The IEBs are the same, but the two routes are in mutual competition as their activation is controlled by the projected components of an applied shear stress necessary to initiate slip along $\boldsymbol{b}_{\mathrm{p} 1}^{\mathrm{hcp}}$ or $\boldsymbol{b}_{\mathrm{p} 2}^{\text {hcp }}$. Consequently, there are two EEBs for the SF mode. Analogous arguments apply to all displacement vectors in I and II and all further stages $(\eta \geqslant 1)$ on the sequential faulting pathways. It follows that there are two EEBs for each plastic deformation mode.

The presently determined GSFEs allow us to distinguish between four deformation modes on $(0002)_{\mathrm{hcp}}$ planes: SF, SL, nano-fcc plate (NP), and twinlike fault (TF). In terms of our present convention (Sec. II A), SF describes the uncorrelated emission of a leading partial $\boldsymbol{b}_{\mathrm{p} 1}^{\mathrm{hcp}}$ and formation of a new, isolated ISF. The SL, NP, and TF modes describe the correlated emission of a second leading or trailing partial and require a pre-existing ISF. The SL and TF modes are, respectively, the emission of a $\boldsymbol{b}_{\mathrm{p} 2}^{\mathrm{hcp}}$ partial on the original slip plane removing the ISF and on an adjacent plane forming an STF. NP is accomplished by emission of $\boldsymbol{b}_{\mathrm{p} 1}^{\text {hcp }}$ on the next but one plane containing the original ISF. The IEBs associated with SF, SL, TF, and NP modes are $\gamma_{\text {usf }}^{\text {hcp }}, \gamma_{\text {usf }}^{\text {hcp }}-\gamma_{\text {isf }}^{\text {hcp }}, \gamma_{\text {utf }}^{\text {hcp }}-\gamma_{\text {isf }}^{\text {hcp }}$, and $\gamma_{\text {upf }}^{\text {hcp }}-\gamma_{\text {isf }}^{\text {hcp }}$, respectively.

The EEBs adapted to these four deformation modes and considering equivalency of faulting pathways may be written in concise form as

$$
\begin{aligned}
& \bar{\gamma}_{\mathrm{sf}}^{\mathrm{X}}(\theta)=\frac{\gamma_{\mathrm{usf}}^{\mathrm{hcp}}}{\cos \left(\theta-\delta_{\mathrm{XII}} 60^{\circ}\right)}, \\
& \bar{\gamma}_{\mathrm{np}}^{\mathrm{X}}(\theta)=\frac{\gamma_{\mathrm{upf}}^{\mathrm{hcp}}-\gamma_{\mathrm{isf}}^{\mathrm{hcp}}}{\cos \left(\theta-\delta_{\mathrm{XII}} 60^{\circ}\right)}, \\
& \bar{\gamma}_{\mathrm{sl}}^{\mathrm{X}}(\theta)=\frac{\gamma_{\mathrm{usf}}^{\mathrm{hcp}}-\gamma_{\mathrm{isf}}^{\mathrm{hcp}}}{\cos \left(\theta-\delta_{\mathrm{XI}} 60^{\circ}\right)}, \\
& \bar{\gamma}_{\mathrm{tf}}^{\mathrm{X}}(\theta)=\frac{\gamma_{\mathrm{utf}}^{\mathrm{hcp}}-\gamma_{\mathrm{isf}}^{\mathrm{hcp}}}{\cos \left(\theta-\delta_{\mathrm{XI}} 60^{\circ}\right)},
\end{aligned}
$$

where $\mathrm{X}$ is either I or II. Angle $\theta$ measures the direction of applied in-plane shear clockwise around the [0001] $\mathrm{hcp}$ axis, where $0^{\circ}$ is in the positive $[1 \overline{1} 00]_{\mathrm{hcp}}$ direction and $60^{\circ}$ in the positive $[0 \overline{1} 10]_{\text {hcp }}$ direction [cf. Fig. 1(a)]. $\bar{\gamma}^{\mathrm{I}}$ and $\bar{\gamma}^{\mathrm{II}}$ differ by a $60^{\circ}$ phase factor depending on whether progression along the faulting pathway or its equivalent involves shear in the direction of $\boldsymbol{b}_{\mathrm{p} 1}^{\text {hcp }}$ or $\boldsymbol{b}_{\mathrm{p} 2}^{\text {hcp }}$.

Figure 6(b) shows the EEBs from Eq. (7) for hcp $\mathrm{Cr}_{25} \mathrm{Fe}_{25} \mathrm{Co}_{25} \mathrm{Ni}_{25}$ and $\mathrm{Cr}_{10} \mathrm{Mn}_{30} \mathrm{Fe}_{50} \mathrm{Co}_{10}$ determined from the GSFEs without superimposed strain. The solid and dashed lines distinguish between the $\bar{\gamma}^{\text {I's }}$ and $\bar{\gamma}^{\mathrm{II}}$ 's, respectively. The activated deformation mode as a function of $\theta$ is indicated by a colored bar.

In $\mathrm{Cr}_{25} \mathrm{Fe}_{25} \mathrm{Co}_{25} \mathrm{Ni}_{25}$, the NP and SL modes are activated corresponding to division into three $\theta$ domains: In a first interval at low angles of $\theta \leqslant 20^{\circ}$ and a second interval at high angles of $\theta \geqslant 40^{\circ} \mathrm{NP}$ is activated. The former interval is due to $\bar{\gamma}_{n p}^{\text {I }}$ and the latter interval due to $\bar{\gamma}_{\mathrm{np}}^{\mathrm{II}}$. The SL mode occurs at intermediate $\theta$ values due to $\bar{\gamma}_{\mathrm{sl}}^{\mathrm{I}}$ in $20^{\circ} \leqslant \theta \leqslant 30^{\circ}$ and $\bar{\gamma}_{\text {sl }}^{\text {II }}$ in $30^{\circ} \leqslant \theta \leqslant 40^{\circ}$. The total deformation mode fractions are $f_{\mathrm{np}}=0.67$ and $f_{\mathrm{sl}}=0.33$. In $\mathrm{Cr}_{10} \mathrm{Mn}_{30} \mathrm{Fe}_{50} \mathrm{Co}_{10}$ only SL is activated as the IEB for SL lowers relative to that of NP so that $\bar{\gamma}_{\mathrm{sl}}^{\mathrm{I} / \mathrm{II}}(\theta)<\bar{\gamma}_{\mathrm{np}}^{\mathrm{I} / \mathrm{II}}(\theta)$ for all $\theta$. The three other considered HEAs exhibit qualitatively similar behavior with intermediate deformation mode fractions, i.e., $f_{\mathrm{sl}}$ is 0.64 in $\mathrm{Cr}_{20} \mathrm{Mn}_{20} \mathrm{Fe}_{20} \mathrm{Co}_{20} \mathrm{Ni}_{20}, 0.85$ in $\mathrm{Cr}_{20} \mathrm{Mn}_{20} \mathrm{Fe}_{30} \mathrm{Co}_{20} \mathrm{Ni}_{10}$, and 0.91 in $\mathrm{Cr}_{20} \mathrm{Mn}_{20} \mathrm{Fe}_{34} \mathrm{Co}_{20} \mathrm{Ni}_{6}$ (NP mode fractions are $f_{\text {np }}=$ $\left.1-f_{\mathrm{sl}}\right)$. It should be noted that as both the NP and SL modes 
require a pre-existing ISF, overcoming the activation barrier for a leading partial to form an ISF is the limiting step for the activation of NP and SL modes.

These findings suggest that basal slip by complete $a_{\mathrm{hcp}} / 3[1 \overline{2} 10]$ dislocations is a primary carrier of plastic deformation on $(0002)_{\text {hcp }}$ slip planes. The activation of NP as another primary deformation mode in all the alloys but $\mathrm{Cr}_{10} \mathrm{Mn}_{30} \mathrm{Fe}_{50} \mathrm{Co}_{10}$ suggests that ISFs formed in the hcp matrix grow into thin metastable fcc plates by successive nucleation processes, in which the hcp phase and the induced fcc plates assume the SN orientation relationship. Growth of the fcc plates by thickening would raise the Gibbs energy per unit area by an amount that approximately linearly increases with plate thickness, suggesting that such plates remain thin. Such stress-induced transformation from the stable hcp phase to a lamellar microstructure containing metastable fcc plates and $\mathrm{SN}$ orientation relationship were observed in $\mathrm{Hf}$ and $\mathrm{Zr}$ during a cold-rolling process (with plate thickness up to several tenth $\mathrm{nm})[43,44]$ and suggested for some of the considered HEAs, see below.

We turn to the effect of superimposed strain on the competition between SF, NP, SL, and TF modes. Figure 7(b) shows the predicted deformation mode fractions associated with the activated deformation modes in hep $\mathrm{Cr}_{20} \mathrm{Mn}_{20} \mathrm{Fe}_{20} \mathrm{Co}_{20} \mathrm{Ni}_{20}$ and $\mathrm{Cr}_{10} \mathrm{Mn}_{30} \mathrm{Fe}_{50} \mathrm{Co}_{10}$. SL and NP are the two activated deformation modes, but their deformation mode fractions sensitively depend on strain level. $f_{\text {np }}$ decreases with the magnitude of compressive strain and increases with larger tensile strain level applied in the three states of strain. By comparison with Figs. 4 and 5, one realizes that $f_{\text {np }}$ correlates closely with the relative stability of the hcp phase if measured by $\gamma_{\mathrm{spf}}^{\text {hcp }}$ (or

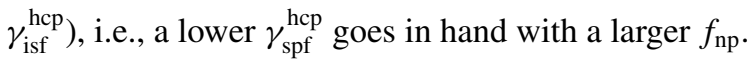

\section{Comparison to experimentally observed deformation mechanisms}

We begin with summarizing the experimentally observed deformation mechanisms for $\mathrm{Cr}_{10} \mathrm{Mn}_{30} \mathrm{Fe}_{50} \mathrm{Co}_{10}$ HEA. Homogenized and as-quenched samples revealed a compositionally equivalent two-phase alloy composed of an fcc matrix, containing a large number of initial stacking faults and hcp laminate layers $[5,11]$. Room-temperature tensile deformation activated multiple plastic deformation mechanisms: In the fcc phase martensitic transformation to the hcp phase occurred, new stacking faults were formed (deformation faulting), and dislocation slip was activated. Deformation twinning was not observed. Plasticity in the hcp phase contributed to strain accommodation with dislocation slip and deformation twinning as well as formation of stacking faults. The types of active dislocations in the fcc phase were not reported, but the observation of stacking faults is consistent with splitting (part) of $a_{\mathrm{fcc}} / 2\langle 1 \overline{1} 0\rangle$ dislocations into $a_{\mathrm{fcc}} / 6\langle 11 \overline{2}\rangle$ partials. Lu et al. [40] added that hcp $\mathrm{Cr}_{10} \mathrm{Mn}_{30} \mathrm{Fe}_{50} \mathrm{Co}_{10}$ blocks contained fcc nanolaminates along $(0002)_{\text {hcp }}$ habit planes. The experimental evidence indicated that these fcc nanolaminates formed due to a reverse, mechanically induced martensitic transformation from the hcp phase to the fcc phase inside the hcp blocks. While the mechanism of reverse martensitic transformation was not further investigated, the authors suggested that it occurred via nucleation and glide of Shockley partials on every second (0002) $)_{\text {hep }}$ plane, similar to the mechanisms described above. Focusing on active dislocations in the hcp phase of $\mathrm{Cr}_{10} \mathrm{Mn}_{30} \mathrm{Fe}_{50} \mathrm{Co}_{10}$, Bu et al. observed $\langle a\rangle$, $\langle c\rangle$, and $\langle c+a\rangle$ type dislocations [77]. $\langle a\rangle$ type dislocations were reported to be complete lattice dislocations $\mathrm{Bu}$ et al. did not report on splitting of complete $a_{\mathrm{hcp}} / 3\langle 1 \overline{2} 10\rangle$ dislocations into $a_{\mathrm{hcp}} / 3\langle\overline{1} 100\rangle$ partials, but the mechanism suggested to accomplish the hcp to fcc transformation would require that dissociation on basal planes occurs.

Our present theoretical results and these previous experimental findings for $\mathrm{Cr}_{10} \mathrm{Mn}_{30} \mathrm{Fe}_{50} \mathrm{Co}_{10}$ are consistent in that deformation faulting, fcc to hcp martensitic transformation, and dislocation slip occur as primary deformation modes in the metastable fcc phase, whereas glide on $(0002)_{\text {hcp }}$ planes is by complete lattice dislocations. Our results predict that the reverse hcp to fcc martensitic transformation could take place in a tensile-strained environment, which may occur as a result of locally high stress concentrations. It should be noted that the DFT overbinding error in $\mathrm{Cr}_{10} \mathrm{Mn}_{30} \mathrm{Fe}_{50} \mathrm{Co}_{10}$ HEAs underestimates the experimental lattice parameters and atomic volumes; see Ref. [66] and Appendix B. Using the experimental volume of the hcp phase as zero strain reference is equivalent to applying a large positive volumetric strain to the present theoretical equilibrium parameters. The trends displayed in Fig. 7(b) suggest that such condition favors the activation of the reverse hcp to fcc martensitic transformation.

We turn to $\mathrm{Cr}_{20} \mathrm{Mn}_{20} \mathrm{Fe}_{34} \mathrm{Co}_{20} \mathrm{Ni}_{6}$ HEA. The phase composition of homogenized and as-quenched $\mathrm{Cr}_{20} \mathrm{Mn}_{20} \mathrm{Fe}_{34} \mathrm{Co}_{20} \mathrm{Ni}_{6}$ dual-phase alloy was mostly fcc (94 vol.\% fraction) with an initially high density of stacking faults and a minor fraction of hep (balance) [11]. Deformation-induced displacive transformation from the fcc phase to the hcp phase and dislocation plasticity were reported as primary deformation modes at room temperature, whereas deformation twinning was not observed. The types of active dislocations were not reported, but the existence of stacking faults in the fcc phase is consistent with splitting (part) of complete $a_{\mathrm{fcc}} / 2\langle 1 \overline{1} 0\rangle$ dislocations into $a_{\mathrm{fcc}} / 6\langle 11 \overline{2}\rangle$ Shockley partials. As stacking faults observed in the retained fcc phase showed similar crystallographic orientation as the deformation induced hcp laminates, it was suggested that the fcc to hcp martensitic transformation proceeded by nucleation and glide of Shockley partials on every other $\{111\}_{\text {fcc }}$ plane. These experimental findings and our present theoretical results for $\mathrm{Cr}_{20} \mathrm{Mn}_{20} \mathrm{Fe}_{34} \mathrm{Co}_{20} \mathrm{Ni}_{6}$ are consistent in that deformation faulting, fcc to hep martensitic transformation, and dislocation slip occur as primary deformation modes in the metastable fcc phase.

We continue with $\mathrm{Cr}_{20} \mathrm{Mn}_{20} \mathrm{Fe}_{20} \mathrm{Co}_{20} \mathrm{Ni}_{20}$ HEA. The $\mathrm{Cr}_{20} \mathrm{Mn}_{20} \mathrm{Fe}_{20} \mathrm{Co}_{20} \mathrm{Ni}_{20}$ alloy in the single fcc phase exhibited exclusively planar dislocation glide of complete $a_{\mathrm{fcc}} / 2\langle 1 \overline{1} 0\rangle$ lattice dislocations at small tensile strains below $\approx 2 \%$ [70]. In addition to complete lattice dislocations, stacking faults were observed after small plastic deformations and attributed to splitting into Shockley partials. Deformation twinning at RT was observed close to fracture strain (above 20\% true tensile strain), but it frequently occurred at much lower strains (above about $7 \%$ true tensile strain) when deformed at $77 \mathrm{~K}$ [70,78]. High-pressure torsion of $\mathrm{Cr}_{20} \mathrm{Mn}_{20} \mathrm{Fe}_{20} \mathrm{Co}_{20} \mathrm{Ni}_{20}$ samples at RT exhibited deformation twins, but not at $77 \mathrm{~K}$ 
[10], and the hcp to fcc transformation was not observed at RT.

These experimental findings and our present theoretical results for $\mathrm{Cr}_{20} \mathrm{Mn}_{20} \mathrm{Fe}_{20} \mathrm{Co}_{20} \mathrm{Ni}_{20}$ are consistent in that full dislocation slip, stacking faults, and fec to hep martensitic transformation occur as primary deformation modes in the fcc phase. The experimental results indicate that deformation twinning is also a primary mode of deformation. Our theoretical results predict deformation twinning only in a tensile-strained environment, which may occur as a result of locally high stress concentrations. DFT again underestimates the atomic volume of fcc $\mathrm{Cr}_{20} \mathrm{Mn}_{20} \mathrm{Fe}_{20} \mathrm{Co}_{20} \mathrm{Ni}_{20}$ HEAs, Ref. [66] and Appendix B. The trends in Fig. 7(a) suggest that the TW mode can be activated in less tensile-strained environments relative to using the experimental volume as zero strain reference.

We turn to $\mathrm{Cr}_{25} \mathrm{Fe}_{25} \mathrm{Co}_{25} \mathrm{Ni}_{25}$ HEA. The initial phase composition of $\mathrm{Cr}_{25} \mathrm{Fe}_{25} \mathrm{Co}_{25} \mathrm{Ni}_{25}$ alloy was a pure fcc phase [79]. Extensive dislocation activity and a small amount of deformation twinning occurred when deformed at RT, while deformation twinning was extensive at $4.2 \mathrm{~K}$ and $77 \mathrm{~K}$. The density of stacking faults increases with lower deformation temperature. Nanometer-thin hcp lamellae were seen after plastic deformation at $77 \mathrm{~K}$, but the amount of hop phase formed was insignificant to exhibit any obvious dislocation activity. The fcc phase and induced hcp phase possessed the SN orientation relationship, and the hcp lamellae were suggested to form via the glide of Shockley partial dislocations on every other $\{111\}_{\text {fcc }}$ plane.

These experimental findings and our present theoretical results for $\mathrm{Cr}_{25} \mathrm{Fe}_{25} \mathrm{Co}_{25} \mathrm{Ni}_{25}$ are consistent in that dislocation slip and fcc to hcp martensitic transformation occur as primary deformation modes in the fcc phase. The experimental results indicate that deformation twinning is also a primary mode of deformation, whereas our theoretical results do not predict deformation twinning. Figure 6(a) shows that $\bar{\gamma}_{\text {sf }}$ and $\bar{\gamma}_{\text {tw }}$ are energetically very close in fcc $\mathrm{Cr}_{25} \mathrm{Fe}_{25} \mathrm{Co}_{25} \mathrm{Ni}_{25}$ in the absence of superimposed strain. Although GSFEs with superimposed strain were not determined for this alloy, tensile strain is expected to alter the competition between SF and TW in favor of TW, similar to the trends displayed in Fig. 7(a) for $\mathrm{Cr}_{20} \mathrm{Mn}_{20} \mathrm{Fe}_{20} \mathrm{Co}_{20} \mathrm{Ni}_{20}$ and $\mathrm{Cr}_{10} \mathrm{Mn}_{30} \mathrm{Fe}_{50} \mathrm{Co}_{10}$. Finally, the microstructural evolution of $\mathrm{Cr}_{20} \mathrm{Mn}_{20} \mathrm{Fe}_{30} \mathrm{Co}_{20} \mathrm{Ni}_{10}$ has not been reported yet, to the best of our knowledge.

\section{Universal scaling rule}

In this section we neglect the superscripts 'fcc' and 'hcp' as we either focus on the totality of planar fault energies or they are obvious from context. Most theoretically examined transition and simple metals in their equilibrium fcc phase satisfy an approximate scaling rule between $\gamma_{\text {usf }}, \gamma_{\text {isf }}$, and $\gamma_{\text {uff }}$ [80,81], viz.

$$
\frac{\gamma_{\mathrm{utf}}}{\gamma_{\mathrm{usf}}} \simeq \frac{1}{2} \frac{\gamma_{\mathrm{isf}}}{\gamma_{\mathrm{usf}}}+1
$$

In Fig. 8(a) we examine this rule for the fcc and hcp phases of $\mathrm{Cr}_{20} \mathrm{Mn}_{20} \mathrm{Fe}_{20} \mathrm{Co}_{20} \mathrm{Ni}_{20}$ and $\mathrm{Cr}_{10} \mathrm{Mn}_{30} \mathrm{Fe}_{50} \mathrm{Co}_{10}$ using the totality of data points determined at equilibrium and under strain. As is evident, the plot suggests a strong positive (a)

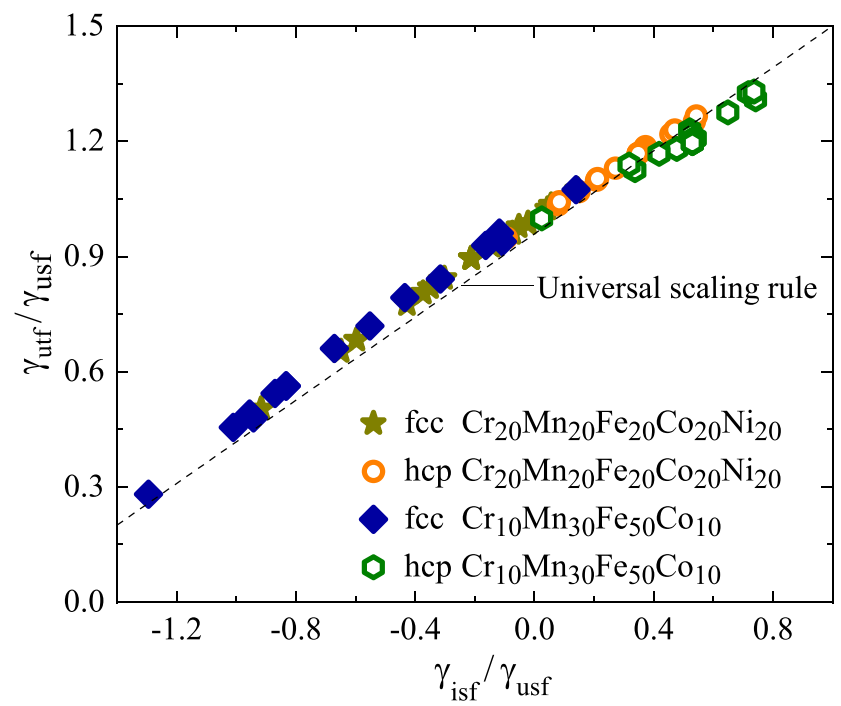

(b)

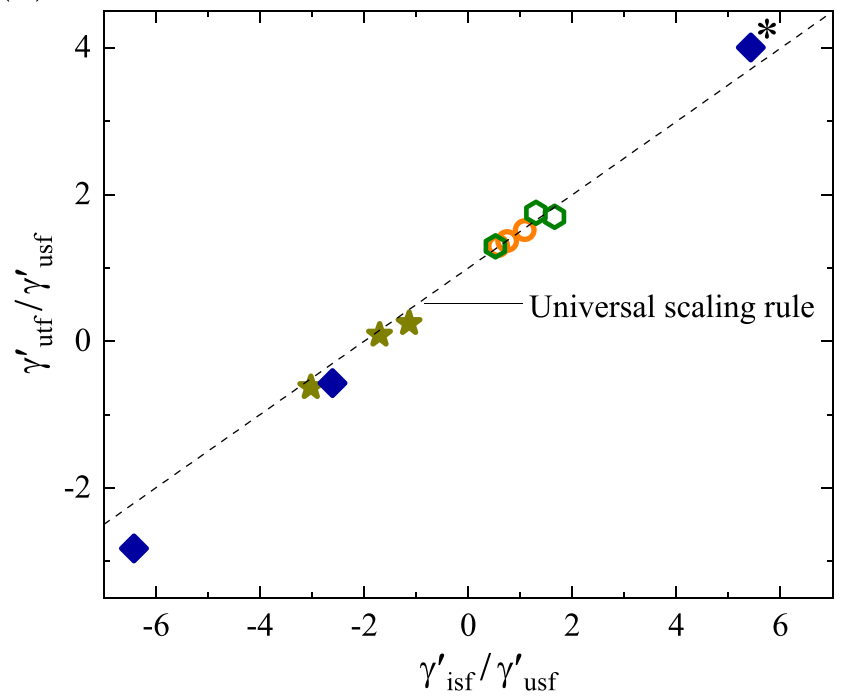

FIG. 8. (a) Scaling plot of stable and unstable fault energies of the GSFE for $\mathrm{Cr}_{20} \mathrm{Mn}_{20} \mathrm{Fe}_{20} \mathrm{Co}_{20} \mathrm{Ni}_{20}$ and $\mathrm{Cr}_{10} \mathrm{Mn}_{30} \mathrm{Fe}_{50} \mathrm{Co}_{10}$ in their fcc and hcp phases at equilibrium and under strain. The dashed line indicates the universal scaling rule [Eq. (8)] proposed for the absence of superimposed strain. (b) Analogous to (a) but for the zero-strain derivatives, where $\gamma^{\prime}$ is short for $d \gamma /\left.d \epsilon\right|_{0}$. The dashed line indicates the universal scaling rule derived from Eq. (9). The data point marked by $*$ was scaled by a factor of 0.5 for displaying purposes.

correlation between $\frac{\gamma_{\text {uff }}}{\gamma_{\text {usf }}}$ and $\frac{\gamma_{\text {sif }}}{\gamma_{\text {usf }}}$ with coefficient of determination $R^{2}$ equal to 0.92 . The universal scaling rule is closely fulfilled for both positive and negative ISF energies. Equation (8) implies that the fault energy barrier experienced by the twinning partial weakly interacts with the pre-existing ISF due to short-ranged interactions between close-packed layers, which is generally consistent with the notion of short-ranged $d$ bonding in transition metals and alloys.

It should be noted that the similar magnitudes of $\gamma_{\text {upf }}-\gamma_{\text {isf }}$ and $\gamma_{\text {usf }}$ in the hcp phase, as evident from Figs. 3(b) and 6, further suggests short-ranged interlayer interactions between (0002) hcp planes. Compliance with the universal scaling rule 


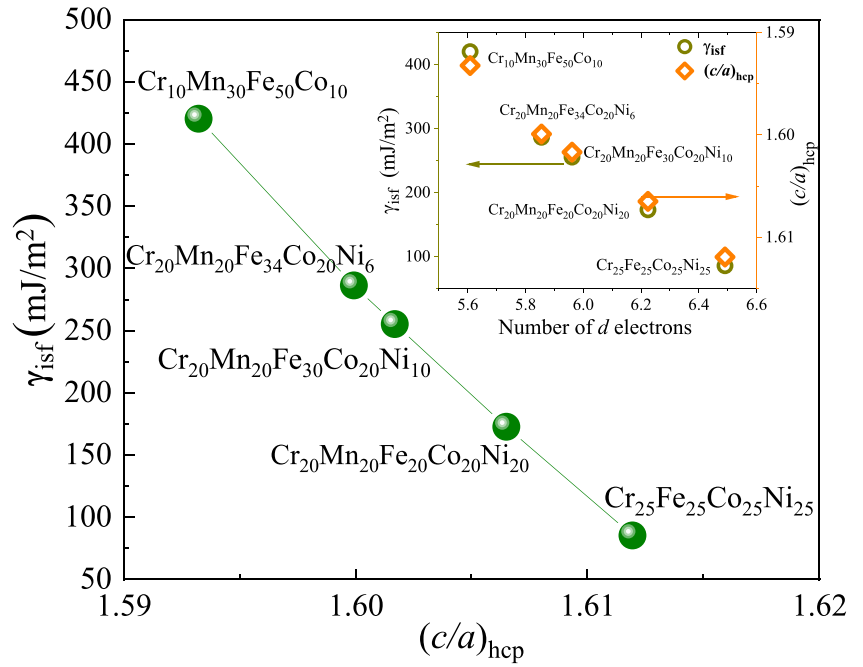

FIG. 9. Inverse relationship between $\gamma_{\text {isf }}^{\text {hcp }}$ and $(c / a)_{\text {hcp }}$ ratio in the hcp phase. The inset shows both quantities plotted as a function of the average number of $3 d$ electrons. The line guides the eye.

thus explains several findings from Sec. III B. First, $\gamma_{\text {usf }}$ is approximately equal to $\gamma_{\text {utf }}$ when $\gamma_{\text {isf }} \approx 0 \mathrm{~mJ} / \mathrm{m}^{2}$, i.e., at the largest considered tensile strains $\epsilon$. Second, $\gamma_{\text {usf }}$ and $\gamma_{\text {utf }}$ are dissimilar when the magnitude of $\gamma_{\text {isf }}$ is large, i.e., at the largest considered compressive strains. Third, for positive except the lowest $\gamma_{\text {isf }}, \gamma_{\text {usf }}$ is smaller than $\gamma_{\text {utf }}$, and vice versa for negative $\gamma_{\text {isf }}$.

The strain derivatives of planar fault energies evaluated at zero strain are the simplest and perhaps the most important measures of how sensitive planar fault energies are to small strains. Besides, they offer a convenient way to compare the effect of strain and strain conditions in different materials. We found that the strain derivatives of $\gamma_{\text {isf }}, \gamma_{\text {usf }}$, and $\gamma_{\text {utf }}$ evaluated at zero strain closely satisfy the following relation,

$$
\left.\left.\frac{d \gamma_{\mathrm{utf}}}{d \epsilon}\right|_{0} \simeq \frac{d \gamma_{\mathrm{usf}}}{d \epsilon}\right|_{0}+\left.\frac{1}{2} \frac{d \gamma_{\mathrm{isf}}}{d \epsilon}\right|_{0}
$$

The associated scaling plot [fault energies in Eq. (8) replaced by their strain derivatives] is shown in Fig. 8(b). The totality of hep and fcc data points fitted to the scaling plot has an $R^{2}$ coefficient of 0.83 . The relation in Eq. (9) explains the result from Sec. III B that the zero-strain derivative of $\gamma_{\text {usf }}$ is larger than that of $\gamma_{\text {utf }}$ when $d \gamma_{\text {isf }} /\left.d \epsilon\right|_{0}>0$, while the zero-strain derivative of $\gamma_{\text {usf }}$ is smaller than that of $\gamma_{\text {utf }}$ when $d \gamma_{\text {isf }} /\left.d \epsilon\right|_{0}<0$. The ratio of two planar fault energy derivatives with respect to strain is thus suggested to serve as characteristic material property.

\section{E. Relationship between $\gamma_{\text {isf }}^{\text {hcp }}$ and $(c / a)_{\text {hcp }}$ and possible implication for nonbasal slip}

For the five HEAs investigated here, $\gamma_{\text {isf }}^{\text {hcp }}$ and $(c / a)_{\text {hcp }}$ have an approximately inverse linear relationship as shown in Fig. 9. That is, the larger $(c / a)_{\text {hcp }}$ the smaller is $\gamma_{\text {isf }}^{\text {hcp }}$. We previously noted [66] that the theoretical $(c / a)_{\text {hcp }}$ ratios of these alloys are consistent with those determined experimentally, although the calculations systematically underestimate the experimental ratios $(c / a)_{\mathrm{hcp}}^{\exp }$ by $1.2-1.4$.
The relationship between $\gamma_{\text {isf }}^{\text {hcp }}$ and $(c / a)_{\text {hcp }}$ can largely be understood by one-electron canonical band theory $[82,83]$. We first verified that $\gamma_{\text {isf }}^{\text {hcp }} A \approx 2 \Delta E_{\text {fcc-hcp }}^{*}$ holds, where $\Delta E_{\text {fcc-hcp }}^{*}$ is defined analogously to Eq. (5b). The canonical band theory for transition metals gives the structure dependence and structural energy dependence of the $d$-band term neglecting hybridization effects with $s$ and $p$ valence bands. Both $(c / a)_{\text {hcp }}$ and the structural energy difference $\Delta E_{\text {fcc-hcp }}^{*}$ are dominantly correlated to the one-electron $d$-band energy and therefore to the $d$-band occupation [84,85]. Furthermore, canonical band theory predicts a regular variation of both parameters with canonical $d$-band filling, wherein the $(c / a)_{\text {hcp }}$ ratio decreases (increases) with respect to the ideal ratio $(\sqrt{8 / 3})$ in the relative stability range of the hcp (fcc) phase. A qualitatively similar result was obtained by Ducastelle and Cyrot-Lackmann using the moment theory of the site-resolved electronic density of states [86].

The canonical inverse relationship between $(c / a)_{\mathrm{hcp}}$ and relative hcp-fcc phase stability remains essentially valid in full DFT calculations, e.g., as corroborated in Refs. [84,85] for the entire transition metal family, as well as the present alloys. Element-specific features of the electronic structure and particularly hybridization effects are, however, responsible that a sign change of $\Delta E_{\text {fcc-hcp }}^{*}$ does not coincide exactly with deviations from the ideal $(c / a)_{\mathrm{hcp}}$ ratio.

The inset of Fig. 9 shows that $\gamma_{\text {isf }}^{\text {hcp }}$ decreases with $3 d$-band filling for the five considered alloys, while $(c / a)_{\mathrm{hcp}}$ increases. Here, the band filling is the compositional average over the alloy components in their alloyed phase. The approximately linear trends of $\gamma_{\text {isf }}^{\text {hcp }}$ and $(c / a)_{\text {hcp }}$ with $3 d$-band filling are incidental and originate from the particular band filling values. These curves suggests that band filling may serve as a simple parameter to tailor $(c / a)_{\text {hcp }}$ and $\gamma_{\text {isf }}^{\text {hcp }}$ in the hcp solid solution phase of HEAs consisting of $\mathrm{Cr}, \mathrm{Mn}, \mathrm{Fe}, \mathrm{Co}$, and Ni. The more easily accessible VEC is nearly linearly related to the $d$-band filling, implying that the VEC may be employed in lieu of the band filling to tailor these quantities.

The compositional trend of $(c / a)_{\text {hcp }}$ shown in Fig. 9 can be approximated using theoretical structure information for the constituent elements in their hcp phases. We determined for paramagnetic $\mathrm{Cr}, \mathrm{Ni}, \mathrm{Co}, \mathrm{Mn}$, and Fe a $(c / a)_{\mathrm{hcp}}$ of 1.763 , $1.638,1.620,1.622$, and 1.587 , respectively. From these data, the estimated $(c / a)_{\text {hcp }}$ ratios (linear mixture rule) and calculated $(c / a)_{\mathrm{hcp}}$ ratios for the HEAs agree within $2.5 \%$. This suggests that $(c / a)_{\text {hcp }}$ for the HEAs scales with the ratios of their constituents elements.

Geometrical aspects, in particular the $(c / a)_{\mathrm{hcp}}$ ratio, and energetic aspects, such as the stacking fault energy, have been identified as important intrinsic factors to select basal and nonbasal dislocation glide systems in hep metals and alloys $[17,77,87]$. In general, a regime is sought after where both $\langle a\rangle$ and $\langle c+a\rangle$ slip can be promoted to overcome intrinsic brittleness and texture sensitivity typical to hcp elements and alloys.

Multiple dislocation modes ( $\langle a\rangle,\langle c\rangle$, and $\langle c+a\rangle$ slip) and frequent cross slip were reported to be active in the hcp phase of $\mathrm{Cr}_{10} \mathrm{Mn}_{30} \mathrm{Fe}_{50} \mathrm{Co}_{10}$ [77], whose experimental $(c / a)_{\text {hcp }}^{\text {exp }}$ ratio is 1.616. Metals with very similar ratio, i.e., $\mathrm{Mg}$, $\mathrm{Co}$, and $\operatorname{Re}\left[(c / a)_{\mathrm{hcp}}^{\exp }\right.$ of $1.624,1.621$, and 1.615, respectively], show 
predominantly basal $\langle a\rangle$ dislocation glide at RT [17]. Thus, the geometrical $(c / a)_{\text {hcp }}$ ratio alone does not conclusively indicate the predominantly activated crystallographic deformation mode in the hcp phase of these materials.

Interestingly, the values of the ISF energies of $\mathrm{Cr}_{10} \mathrm{Mn}_{30} \mathrm{Fe}_{50} \mathrm{Co}_{10}$ and those of the elements $\mathrm{Mg}, \mathrm{Co}$, and Re differ significantly. Referring to theoretical literature values, $\mathrm{Mg}$ has low $\gamma_{\text {isf }}^{\text {hcp }}\left(\sim 26-36 \mathrm{~mJ} / \mathrm{m}^{2}\right.$, cf. Appendix A), while Co $\left(\sim 60-170 \mathrm{~mJ} / \mathrm{m}^{2}[51]\right)$ and $\operatorname{Re}\left(\sim 206 \mathrm{~mJ} / \mathrm{m}^{2}\right.$ [88]) have intermediate values. For $\mathrm{Cr}_{10} \mathrm{Mn}_{30} \mathrm{Fe}_{50} \mathrm{Co}_{10}$, we found a high value of $\gamma_{\text {isf }}^{\text {hcp }}=420 \mathrm{~mJ} / \mathrm{m}^{2}$. This large spread in ISF energy is expected to result in different dislocation core structures and cross-slip behavior. As mentioned above, perfect basal dislocations can dissociate into two Shockley partials bounding an ISF, wherein the width of the stacking fault ribbon is inversely correlated to the value of $\gamma_{\text {isf }}^{\text {hcp }}$. Constriction of this ribbon is necessary for cross slip to operate, which may be aided by increased stacking fault energy. The frequent cross slip observed in the hcp phase of $\mathrm{Cr}_{10} \mathrm{Mn}_{30} \mathrm{Fe}_{50} \mathrm{Co}_{10}$ thus appears to be consistent with its high ISF energy. Further investigations of GSFEs on prism and pyramidal planes are needed to understand the potential activity of prism $\langle a\rangle$ and $\langle c+a\rangle$ dislocations.

\section{SUMMARY AND CONCLUSIONS}

We presented a DFT investigation of GSFEs in five polymorphic, four- and five-component HEAs composed of $\mathrm{Cr}$, $\mathrm{Mn}, \mathrm{Fe}, \mathrm{Co}$, and $\mathrm{Ni}$ in their compositionally equivalent $\mathrm{fcc}$ and hcp phases. Specifically, we considered configurationaveraged GSFEs along sequential faulting pathways associated with dislocation slip on $\{111\}_{\mathrm{fcc}}$ and $(0002)_{\mathrm{hcp}}$ close-packed planes.

We dedicated a detailed study to the influence of volumetric and longitudinal superimposed strains (up to a strain parameter of $\epsilon= \pm 0.1$ ) on the stable and unstable stacking fault energies of $\mathrm{Cr}_{20} \mathrm{Mn}_{20} \mathrm{Fe}_{20} \mathrm{Co}_{20} \mathrm{Ni}_{20}$ and $\mathrm{Cr}_{10} \mathrm{Mn}_{30} \mathrm{Fe}_{50} \mathrm{Co}_{10}$. We demonstrated that already the application of mild strains has significant effects on the planar fault energies in both close-packed phases. Nonmonotonic dependencies on strain occurred in the fcc phases, whereas only monotonic trends appeared in the hcp phase. We showed that the stacking fault energies $\gamma_{\text {isf }}, \gamma_{\text {usf }}$, and $\gamma_{\text {utf }}$ in these two HEAs and both phases are closely related in how they change with superimposed lattice strains. The ratio of two of these energies can thus serve as characteristic material property (universal scaling relation). We found an approximately inverse linear relationship between $\gamma_{\text {isf }}^{\text {hcp }}$ and $(c / a)_{\text {hcp }}$ for the presently considered alloys and explained it via band theory.

We discussed the implications of our results for the fcc versus hcp phase stability and predicted activated plastic deformation modes for all the investigated alloys in the absence of lattice strain, as well as the effect of superimposed strain for $\mathrm{Cr}_{20} \mathrm{Mn}_{20} \mathrm{Fe}_{20} \mathrm{Co}_{20} \mathrm{Ni}_{20}$ and $\mathrm{Cr}_{10} \mathrm{Mn}_{30} \mathrm{Fe}_{50} \mathrm{Co}_{10}$. Our predictions were compared with experimentally observed deformation mechanisms.

Our results suggest that the resistance to partial dislocation emission, as measured by IEBs, and the relative frequency of active plastic deformation modes in strained lattice environments can be starkly different from unstrained counterparts. Localized, highly strained environments can, for instance, occur in grain boundaries of nanocrystalline materials as a result of anomalous local stress intensities including hydrostatic pressure and deviatoric stresses [35].

While understanding the implications of how the GSFE depends on strain or stress is important in the context of metals and alloys subject to high pressure, during severe plastic deformation or high strain-rate deformation, dislocation activity in nanocrystalline systems, etc., the obtained results are also useful in the mechanical analysis of dislocation nucleation from a crack-tip or grain boundary in regard to accounting for tension-shear coupling [89]. The results of this study are further valuable for the parametrization of empirical interatomic potentials used to simulate atomistic dislocation dynamics at large stresses, for which fitting to planar fault energies versus strain/stress data is required.

\section{ACKNOWLEDGMENTS}

The Swedish Research Council (Grants Agreement No. 2016-00236, No. 2017-06474, No. 2019-04971, and No. 2020-03736), the Swedish Steel Producers' Association, the Swedish Foundation for Strategic Research, the Swedish Energy Agency, and the Hungarian Scientific Research Fund (research project OTKA 109570) are acknowledged for financial support. X.L. also gratefully acknowledges financial support from the Göran Gustafssons Stiftelse. The computations were performed on resources provided by the Swedish National Infrastructure for Computing (SNIC) at the National Supercomputer Centre in Linköping partially funded by the Swedish Research Council through Grant Agreement No. 2018-05973.

TABLE I. Special stationary points of the GSFE (in $\mathrm{mJ} / \mathrm{m}^{2}$ ) for fcc $\mathrm{Cu}$ and hcp $\mathrm{Mg}$ obtained in this work, other theoretical results, and experimental values (distinguished by Expt.).

\begin{tabular}{|c|c|c|c|c|c|}
\hline & & $\gamma_{\mathrm{usf}}^{\mathrm{fcc}}$ & $\gamma_{\mathrm{isf}}^{\mathrm{fcc}}$ & $\gamma_{\mathrm{utf}}^{\mathrm{fcc}}$ & $\gamma_{\mathrm{esf}}^{\mathrm{fcc}}$ \\
\hline \multirow{9}{*}{$\mathrm{Cu}$} & This work & 199.9 & 47.1 & 227.4 & 52.9 \\
\hline & Ref. [92] & 181.0 & 41.0 & 200.0 & \\
\hline & Ref. [93] & 210.0 & 49.0 & & \\
\hline & Ref. [94] & 180.0 & & 210.0 & \\
\hline & Ref. [36] & & 41.0 & & \\
\hline & Ref. [41] & & 39.0 & & \\
\hline & Expt. [95] & & 45 & & \\
\hline & Expt. [96] & & 50 & & \\
\hline & & $\gamma_{\text {usf }}^{\text {hcp }}$ & $\gamma_{\text {isf }}^{\text {hcp }}$ & $\gamma_{\mathrm{utf}}^{\mathrm{hcp}}$ & $\gamma_{\mathrm{stf}}^{\mathrm{hcp}}$ \\
\hline \multirow{8}{*}{$\mathrm{Mg}$} & This work & 97.2 & 29.1 & 115.9 & 36.4 \\
\hline & Ref. [13] & 93.6 & 33.9 & 114.5 & 41.4 \\
\hline & Ref. [97] & 92.0 & 36.0 & 111.0 & 39.0 \\
\hline & Ref. [98] & 92.0 & 33.0 & 110.0 & 42.0 \\
\hline & Ref. [99] & 94.9 & 26.1 & 111.2 & 37.1 \\
\hline & Ref. [100] & & 30.0 & & 40.0 \\
\hline & Expt. [101] & & $>50$ & & \\
\hline & Expt. [102] & & $60-150$ & & \\
\hline
\end{tabular}


TABLE II. Zero-temperature equilibrium lattice parameters (in $\AA$ ) for HEAs in their fcc and hcp phases from present theory in comparison with room temperature experimental data. The error of the theoretical values relative to the experimental data (arithmetic average in the case of multiple experimental data) is stated in parentheses, where applicable.

\begin{tabular}{|c|c|c|c|c|c|c|}
\hline \multirow[b]{3}{*}{ HEA } & \multicolumn{2}{|c|}{ fcc phase } & \multicolumn{4}{|c|}{ hcp phase } \\
\hline & \multirow{2}{*}{$\begin{array}{c}\text { theory } \\
a_{\mathrm{fcc}}\left(\Delta a_{\mathrm{fcc}}\right)\end{array}$} & \multirow{2}{*}{$\begin{array}{c}\text { experiment } \\
a_{\mathrm{fcc}} \\
\end{array}$} & \multicolumn{2}{|c|}{ theory } & \multicolumn{2}{|c|}{ experiment } \\
\hline & & & $a_{\mathrm{hcp}}\left(\Delta a_{\mathrm{hcp}}\right)$ & $c_{\mathrm{hcp}}\left(\Delta c_{\mathrm{hcp}}\right)$ & $a_{\mathrm{hcp}}$ & $c_{\mathrm{hcp}}$ \\
\hline $\mathrm{Cr}_{10} \mathrm{Mn}_{30} \mathrm{Fe}_{50} \mathrm{Co}_{10}$ & $3.503(-0.029)$ & $3.608[77]$ & $2.478(-0.026)$ & $3.948(-0.039)$ & $2.544[77]$ & $4.110[77]$ \\
\hline $\mathrm{Cr}_{20} \mathrm{Mn}_{20} \mathrm{Fe}_{34} \mathrm{Co}_{20} \mathrm{Ni}_{6}$ & 3.517 & & 2.487 & 3.979 & & \\
\hline $\mathrm{Cr}_{20} \mathrm{Mn}_{20} \mathrm{Fe}_{30} \mathrm{Co}_{20} \mathrm{Ni}_{10}$ & 3.519 & & 2.488 & 3.985 & & \\
\hline $\mathrm{Cr}_{20} \mathrm{Mn}_{20} \mathrm{Fe}_{20} \mathrm{Co}_{20} \mathrm{Ni}_{20}$ & $3.529(-0.019)$ & $\begin{array}{l}3.597[12] \\
3.597[103]\end{array}$ & $2.493(-0.018)$ & $4.005(-0.033)$ & $\begin{array}{l}2.544(1)[12] \\
2.535(2)[13]\end{array}$ & $\begin{array}{l}4.142(3)[12] \\
4.138(1)[13]\end{array}$ \\
\hline $\mathrm{Cr}_{25} \mathrm{Fe}_{25} \mathrm{Co}_{25} \mathrm{Ni}_{25}$ & $3.529(-0.013)$ & $\begin{array}{l}3.575[14] \\
3.574[103]\end{array}$ & $2.497(-0.010)$ & $4.025(-0.022)$ & $2.522[14]$ & $4.118[14]$ \\
\hline
\end{tabular}

\section{APPENDIX A: GENERALIZED STACKING FAULT ENERGIES OF PURE FCC CU AND HCP MG}

To access the accuracy of the EMTO method for GSFE calculations in the fcc and hcp structures, we determined the fault energies of the special stationary points encountered on the faulting pathways introduced in Sec. II A. Pure fcc $\mathrm{Cu}$ and hcp Mg were selected because a large amount of literature data is available for comparison.

The calculated equilibrium lattice parameter of fcc $\mathrm{Cu}$ is $3.638 \AA$. For hcp $\mathrm{Mg}$, we determined $a_{\mathrm{hcp}}=3.203 \AA$ and and $c_{\text {hcp }}=5.205 \AA$. These values are in close agreement with available experimental data $[90,91]$ and previous theoretical results $[36,38]$.

The calculated planar fault energies for $\mathrm{Cu}$ and $\mathrm{Mg}$ along with other theoretical results and RT experimental data for $\gamma_{\text {isf }}^{\text {fcc }}$ are listed in Table I. There, we do not discriminate between relaxed and unrelaxed planar fault energies, since those theoretical studies reported relaxation effects to be small. For both metals, one can see that our results are in close agreement with the theoretical literature data. $\gamma_{\text {isf }}$ for $\mathrm{Cu}$ is close to the experimental values, whereas all theoretical ISF energies for hcp $\mathrm{Mg}$ are smaller than the experimental data. Overall, this assessment indicates that the presently employed method gives an accurate description for the GSFE in fcc and hcp systems.

\section{APPENDIX B: LATTICE PARAMETERS}

Table II presents the employed theoretical equilibrium lattice parameters for the considered HEAs in their fcc and hcp phases from present theory in comparison with room temperature experimental data. Where applicable we also give the error of present theoretical values with respect to experimental lattice parameters. For further discussions we refer the reader to Ref. [66].
[1] J. W. Yeh, S. K. Chen, S. J. Lin, J. Y. Gan, T. S. Chin, T. T. Shun, C. H. Tsau, and S. Y. Chang, Nanostructured high-entropy alloys with multiple principal elements: Novel alloy design concepts and outcomes, Adv. Eng. Mater. 6, 299 (2004).

[2] B. Cantor, I. T. H. Chang, P. Knight, and A. J. B. Vincent, Microstructural development in equiatomic multicomponent alloys, Mater. Sci. Eng. A 375, 213 (2004).

[3] Y. D. Wu, Y. H. Cai, T. Wang, J. J. Si, J. Zhu, Y. D. Wang, and $X$. D. Hui, A refractory $\mathrm{Hf}_{25} \mathrm{Nb}_{25} \mathrm{Ti}_{25} \mathrm{Zr}_{25}$ high-entropy alloy with excellent structural stability and tensile properties, Mater. Lett. 130, 277 (2014).

[4] Y. Zou, S. Maiti, W. Steurer, and R. Spolenak, Size-dependent plasticity in an $\mathrm{Nb}_{25} \mathrm{Mo}_{25} \mathrm{Ta}_{25} \mathrm{~W}_{25}$ refractory high-entropy alloy, Acta Mater. 65, 85 (2014).

[5] Z. Li, K. G. Pradeep, Y. Deng, D. Raabe, and C. C. Tasan, Metastable high-entropy dual-phase alloys overcome the strength-ductility trade-off, Nature (London) 534, 227 (2016).

[6] F. Granberg, K. Nordlund, M. W. Ullah, K. Jin, C. Lu, H. Bei, L. M. Wang, F. Djurabekova, W. J. Weber, and Y. Zhang, Mechanism of Radiation Damage Reduction in Equiatomic
Multicomponent Single Phase Alloys, Phys. Rev. Lett. 116, 135504 (2016).

[7] D. Wei, X. Li, W. Heng, Y. Koizumi, F. He, W. Choi, B. Lee, H. Kim, H. Kato, and A. Chiba, Novel Co-rich high entropy alloys with superior tensile properties, Mater. Res. Lett. 7, 82 (2018).

[8] D. Wei, X. Li, J. Jiang, W. Heng, Y. Koizumi, W. M. Choi, B. J. Lee, H. S. Kim, H. Kato, and A. Chiba, Novel Co-rich high performance twinning-induced plasticity (TWIP) and transformation-induced plasticity (TRIP) high-entropy alloys, Scr. Mater. 165, 39 (2019).

[9] Y. J. Zhao, J. W. Qiao, S. G. Ma, M. C. Gaod, H. J. Yang, M. W. Chen, and Y. Zhang, A hexagonal close-packed highentropy alloy: The effect of entropy, Mater. Des. 96, 10 (2016).

[10] W. Skrotzki, A. Pukenas, E. Odor, B. Joni, T. Ungar, B. Völker, A. Hohenwarter, R. Pippan, and E. P. George, Microstructure, texture, and strength development during high-pressure torsion of $\mathrm{CrMnFeCoNi}$ high-entropy alloy, Crystals 10, 336 (2020).

[11] Z. Li, F. Körmann, B. Grabowski, J. Neugebauer, and D. Raabe, Ab initio assisted design of quinary dual-phase 
high-entropy alloys with transformation-induced plasticity, Acta Mater. 136, 262 (2017).

[12] C. L. Tracy, S. Park, D. R. Rittman, S. J. Zinkle, H. Bei, M. Lang, R. C. Ewing, and W. L. Mao, High pressure synthesis of a hexagonal close-packed phase of the high-entropy alloy CrMnFeCoNi, Nat. Commun. 8, 15634 (2017).

[13] F. Zhang, Y. Wu, H. Lou, Z. Zeng, V. B. Prakapenka, E. Greenberg, Y. Ren, J. Yan, J. S. Okasinski, X. Liu, Y. Liu, Q. Zeng, and Z. Lu, Polymorphism in a high-entropy alloy, Nat. Commun. 8, 15687 (2017).

[14] F. X. Zhang, K. J. S. Zhao, H. Bei, D. Popov, C. Park, J. C. Neuefeind, W. J. Weber, and Y. Zhang, Pressure-induced fcc to hcp phase transition in Ni-based high entropy solid solution alloys, Appl. Phys. Lett. 110, 011902 (2017).

[15] S. Allain, J.-P. Chateau, O. Bouaziz, S. Migot, and N. Guelton, Correlations between the calculated stacking fault energy and the plasticity mechanisms in Fe-Mn-C alloys, Mater. Sci. Eng., A 387-389, 158 (2004), 13th International Conference on the Strength of Materials.

[16] B. C. De Cooman, Y. Estrin, and S. K. Kim, Twinning-induced plasticity (TWIP) steels, Acta Mater. 142, 283 (2018).

[17] J. P. Hirth and J. Lothe, Theory of Dislocations, 2nd ed. (Wiley, New York, 1982).

[18] S. Crampin, K. Hampel, D. D. Vvedensky, and J. M. MacLaren, The calculation of stacking fault energies in closepacked metals, J. Mater. Res. 5, 2107 (1990).

[19] H. Ahlborn and G. Wassermann, Einfluss von Verformungsgrad und Temperatur auf die Textur von Silberdrähten, Z. Metallk. 54, 1 (1963).

[20] A. English and G. Chin, On the variation of wire texture with stacking fault energy in f.c.c. metals and alloys, Acta Metall. 13, 1013 (1965).

[21] M. A. Fortes and B. Ralph, Deformation twinning and double twinning in iridium, J. Less Common Met. 22, 201 (1970).

[22] R. Adamesku, S. Grebenkin, A. Yermakov, and P. Panfilov, On mechanical twinning in iridium under compression at room temperature, J. Mater. Sci. Lett. 13, 865 (1994).

[23] W. Z. Han, G. M. Cheng, S. X. Li, S. D. Wu, and Z. F. Zhang, Deformation Induced Microtwins and Stacking Faults in Aluminum Single Crystal, Phys. Rev. Lett. 101, 115505 (2008).

[24] M. Chen, E. Ma, K. J. Hemker, H. Sheng, Y. Wang, and X. Cheng, Deformation twinning in nanocrystalline aluminum, Science 300, 1275 (2003).

[25] V. Vítek, Intrinsic stacking faults in body-centred cubic crystals, Philos. Mag. A 18, 773 (1968).

[26] B. Li, B. Cao, K. Ramesh, and E. Ma, A nucleation mechanism of deformation twins in pure aluminum, Acta Mater. 57, 4500 (2009).

[27] M. Jo, Y. Koo, B. Lee, B. Johansson, L. Vitos, and S. Kwon, Theory for plasticity of face-centered cubic metals, Proc. Natl. Acad. Sci. 111, 6560 (2014).

[28] W. Li, S. Lu, D. Kim, K. Kokko, S. Hertzman, S. Kwon, and L. Vitos, First-principles prediction of the deformation modes in austenitic Fe-Cr-Ni alloys, Appl. Phys. Lett. 108, 081903 (2016).

[29] A. G. Frøseth, H. V. Swygenhoven, and P. M. Derlet, The influence of twins on the mechanical properties of nc-Al, Acta Mater. 52, 2259 (2004).
[30] H. V. Swygenhoven, P. M. Derlet, and A. G. Frøseth, Stacking fault energies and slip in nanocrystalline metals, Nat. Mater. 3, 399 (2004).

[31] V. Yamakov, D. Wolf, S. R. Phillpot, A. K. Mukherjee, and H. Gleiter, Deformation-mechanism map for nanocrystalline metals by molecular-dynamics simulation, Nat. Mater. 3, 43 (2004).

[32] H. Huang, X. Li, Z. Dong, W. Li, S. Huang, D. Meng, X. Lai, T. Liu, S. Zhu, and L. Vitos, Critical stress for twinning nucleation in CrCoNi-based medium and high entropy alloys, Acta Mater. 149, 388 (2018).

[33] P. Kwasniak, H. Garbacz, and K. Kurzydlowski, Solid solution strengthening of hexagonal titanium alloys: Restoring forces and stacking faults calculated from first principles, Acta Mater. 102, 304 (2016).

[34] M. de Koning, W. Cai, and V. V. Bulatov, Anomalous Dislocation Multiplication in Fcc Metals, Phys. Rev. Lett. 91, 025503 (2003).

[35] C. Brandl, P. M. Derlet, and H. Van Swygenhoven, Generalstacking-fault energies in highly strained metallic environments: Ab initio calculations, Phys. Rev. B 76, 054124 (2007).

[36] P. S. Branicio, J. Y. Zhang, and D. J. Srolovitz, Effect of strain on the stacking fault energy of copper: A first-principles study, Phys. Rev. B 88, 064104 (2013).

[37] P. Heino, L. Perondi, K. Kaski, and E. Ristolainen, Stackingfault energy of copper from molecular-dynamics simulations, Phys. Rev. B 60, 14625 (1999).

[38] S. H. Zhang, I. J. Beyerlein, D. Legut, Z. H. Fu, Z. Zhang, S. L. Shang, Z. K. Liu, T. C. Germann, and R. F. Zhang, First-principles investigation of strain effects on the stacking fault energies, dislocation core structure, and Peierls stress of magnesium and its alloys, Phys. Rev. B 95, 224106 (2017).

[39] D. Rodney, L. Ventelon, E. Clouet, L. Pizzagalli, and F. Willaime, Ab initio modeling of dislocation core properties in metals and semiconductors, Acta Mater. 124, 633 (2017).

[40] W. Lu, C. Liebscher, G. Dehm, D. Raabe, and Z. Li, Bidirectional transformation enables hierarchical nanolaminate dual-phase high-entropy alloys, Adv. Mater. 30-44, e1804727 (2018).

[41] S. Ogata, J. Li, and S. Yip, Ideal pure shear strength of Aluminum and Copper, Science 298, 807 (2002).

[42] Z. Nishiyama, Martensitic Transformation (Academic Press, New York, San Francisco, London, 1978).

[43] H. Zhao, M. Song, S. Ni, S. Shao, J. Wang, and X. Liao, Atomic-scale understanding of stress-induced phase transformation in cold-rolled Hf, Acta Mater. 131, 271 (2017).

[44] H. Zhao, X. Hu, M. Song, and S. Ni, Mechanisms for deformation induced hexagonal close-packed structure to facecentered cubic structure transformation in zirconium, Scr. Mater. 132, 63 (2017).

[45] N. Chetty and M. Weinert, Stacking faults in magnesium, Phys. Rev. B 56, 10844 (1997).

[46] M. H. Yoo, Slip, twinning, and fracture in hexagonal closepacked metals, Metall. Trans. A 12, 409 (1981).

[47] J. W. Christian and S. Mahajan, Deformation twinning, Prog. Mater. Sci. 39, 1 (1995).

[48] S. Kibey, J. Liu, D. Johnson, and H. Sehitoglu, Predicting twinning stress in fcc metals: Linking twin-energy pathways to twin nucleation, Acta Mater. 55, 6843 (2007). 
[49] D. Wei, X. Li, S. Schönecker, J. Jiang, W. M. Choi, B. J. Lee, H. S. Kim, A. Chiba, and H. Kato, Development of strong and ductile metastable face-centered cubic single-phase high-entropy alloys, Acta Mater. 181, 318 (2019).

[50] J. Hartford, B. von Sydow, G. Wahnström, and B. I. Lundqvist, Peierls barriers and stresses for edge dislocations in Pd and Al calculated from first principles, Phys. Rev. B 58, 2487 (1998).

[51] Q.-M. Hu and R. Yang, Basal-plane stacking fault energy of hexagonal close-packed metals based on the ising model, Acta Mater. 61, 1136 (2013).

[52] W. Li, S. Lu, Q. Hu, S. K. Kwon, B. Johansson, and L. Vitos, Generalized stacking fault energies of alloys, J. Phys.: Condens. Matter 26, 265005 (2014).

[53] Y. Dou and J. Zhang, Effects of structural relaxation on the generalized stacking fault energies of hexagonal-close-packed system from first-principles calculations, Comput. Mater. Sci. 98, 405 (2015).

[54] P. Hohenberg and W. Kohn, Inhomogeneous electron gas, Phys. Rev. 136, B864 (1964)

[55] O. K. Andersen, O. Jepsen, and G. Krier, in Lectures on Methods of Electronic Structure Calculations, edited by V. Kumar, O. K. Andersen, and A. Mookerjee (World Scientific, Singapore, 1994), p. 63.

[56] L. Vitos, Total-energy method based on the exact muffin-tin orbitals theory, Phys. Rev. B 64, 014107 (2001).

[57] W. Kohn and L. J. Sham, Self-consistent equations including exchange and correlation effects, Phys. Rev. 140, A1133 (1965).

[58] J. P. Perdew, K. Burke, and M. Ernzerhof, Generalized Gradient Approximation made Simple, Phys. Rev. Lett. 77, 3865 (1996).

[59] L. Vitos, Computational Quantum Mechanics for Materials Engineers (Springer-Verlag, London, 2007).

[60] P. Soven, Coherent-potential model of substitutional disordered alloys, Phys. Rev. 156, 809 (1967).

[61] B. L. Gyorffy, Coherent-potential approximation for a nonoverlapping-muffin-tin-potential model of random substitutional alloys, Phys. Rev. B 5, 2382 (1972).

[62] L. Vitos, I. A. Abrikosov, and B. Johansson, Anisotropic Lattice Distortions in Random Alloys from First-Principles Theory, Phys. Rev. Lett. 87, 156401 (2001).

[63] J. Staunton, B. L. Győrffy, A. J. Pindor, G. M. Stocks, and H. Winter, Electronic structure of metallic ferromagnets above the Curie temperature, J. Phys. F: Met. Phys. 15, 1387 (1985).

[64] B. L. Gyorffy, A. J. Pindor, J. Staunton, G. M. Stocks, and H. Winter, A first-principles theory of ferromagnetic phase transitions in metals, J. Phys. F: Met. Phys. 15, 1337 (1985).

[65] A. J. Pindor, J. Staunton, G. M. Stocks, and H. Winter, Disordered local moment state of magnetic transition metals: A self-consistent KKR CPA calculation, J. Phys. F: Met. Phys. 13, 979 (1983)

[66] X. Li, D. L. Irving, and L. Vitos, First-principles investigation of the micromechanical properties of fcc-hcp polymorphic high-entropy alloys, Sci. Rep. 8, 11196 (2018).

[67] S. Zhao, G. M. Stocks, and Y. Zhang, Stacking fault energies of face-centered cubic concentrated solid solution alloys, Acta Mater. 134, 334 (2017).

[68] P. J. H. Denteneer and W. van Haeringen, Stacking-fault energies in semiconductors from first principles calculations, J. Phys. C 20, L883 (1987).
[69] B. Gludovatz, A. Hohenwarter, D. Catoor, E. H. Chang, E. P. George, and R. O. Ritchie, A fracture-resistant high-entropy alloy for cryogenic applications, Science 345, 1153 (2014).

[70] F. Otto, A. Dlouhý, C. Somsen, H. Bei, G. Eggeler, and E. George, The influences of temperature and microstructure on the tensile properties of a $\mathrm{CoCrFeMnNi}$ high-entropy alloy, Acta Mater. 61, 5743 (2013).

[71] E. B. Tadmor and S. Hai, A Peierls criterion for the onset of deformation twinning at a crack tip, J. Mech. Phys. Solids 51, 765 (2003).

[72] D. H. Warner, W. A. Curtin, and S. Qu, Rate dependence of crack-tip processes predicts twinning trends in f.c.c. metals, Nat. Mater. 6, 876 (2007)

[73] J. R. Rice, Dislocation nucleation from a crack tip: An analysis based on the Peierls concept, J. Mech. Phys. Solids 40, 239 (1992).

[74] B. Li, M. Sui, and S. Mao, Twinnability predication for fcc metals, J. Mater. Sci. Technol. 27, 97 (2011).

[75] W. G. Burgers, On the process of transition of the cubicbody-centered modification into the hexagonal-close-packed modification of zirconium, Physica 1, 561 (1934).

[76] S. Lu, X. Sun, X. An, W. Li, Y. Chen, H. Zhang, and L. Vitos, Theory of transformation-mediated twinning, arXiv:1910.11748 [cond-mat.mtrl-sci].

[77] Y. Bu, Z. Li, J. Liu, H. Wang, D. Raabe, and W. Yang, Nonbasal Slip Systems Enable a Strong and Ductile HexagonalClose-Packed High-Entropy Phase, Phys. Rev. Lett. 122, 075502 (2019).

[78] G. Laplanche, A. Kostka, O. M. Horst, G. Eggeler, and E. P. George, Microstructure evolution and critical stress for twinning in the CrMnFeCoNi high-entropy alloy, Acta Mater. 118, 152 (2016).

[79] Q. Lin, J. Liu, X. An, H. Wang, Y. Zhang, and X. Liao, Cryogenic-deformation-induced phase transformation in an FeCoCrNi high-entropy alloy, Mater. Res. Lett. 6, 236 (2018).

[80] Z. H. Jin, S. T. Dunham, H. Gleiter, H. Hahn, and P. Gumbsch, A universal scaling of planar fault energy barriers in facecentered cubic metals, Scr. Mater. 64, 605 (2011).

[81] S. Schönecker, X. Li, M. Richter, and L. Vitos, Lattice dynamics and metastability of fcc metals in the hcp structure and the crucial role of spin-orbit coupling in platinum, Phys. Rev. B 97, 224305 (2018).

[82] O. K. Andersen, O. Jepsen, and D. Glötzel, Highlights of Condensed-Matter Physics, edited by F. Bassani, F. Fumi, and M. P. Tossi (North-Holland, Amsterdam, 1985), Chap. Canonical description of the band structure of metals, pp. 59-176.

[83] H. L. Skriver, The LMTO method, Springer series in solid-state sciences, Vol. 41 (Springer-Verlag, Berlin, Heidelberg, 1984).

[84] J. X. Zheng-Johansson, O. Eriksson, and B. Johansson, Systematic behavior of the hexagonal axial ratio for the $d$ transition metals, Phys. Rev. B 59, 6131 (1999).

[85] H. L. Skriver, Crystal structure from one-electron theory, Phys. Rev. B 31, 1909 (1985).

[86] F. Ducastelle and F. Cyrot-Lackmann, Moments developments: II. application to the crystalline structures and the stacking fault energies of transition metals, J. Phys. Chem. Solids 32, 285 (1971).

[87] M. H. Yoo, S. R. Agnew, J. R. Morris, and K. M. Ho, Non-basal slip systems in HCP metals and 
alloys: Source mechanism, Mater. Sci. Eng. A 319-321, 87 (2001).

[88] B. Yin, Z. Wu, and W. A. Curtin, Comprehensive firstprinciples study of stable stacking faults in hcp metals, Acta Mater. 123, 223 (2017).

[89] Y. Sun, G. E. Beltz, and J. R. Rice, Estimates from atomic models of tension-shear coupling in dislocation nucleation from a crack tip, Mater. Sci. Eng. A 170, 67 (1993).

[90] I.-K. Suh, H. Ohta, and Y. Waseda, High-temperature thermal expansion of six metallic elements measured by dilatation method and X-ray diffraction, J. Mater. Sci. 23, 757 (1988).

[91] F. W. V. Batchelder and R. F. Raeuchle, Lattice constants and Brillouin zone overlap in dilute magnesium alloys, Phys. Rev. 105, 59 (1957).

[92] S. Kibey, J. B. Liu, D. D. Johnson, and H. Sehitoglu, Generalized planar fault energies and twinning in $\mathrm{Cu}-\mathrm{Al}$ alloys, Appl. Phys. Lett. 89, 191911 (2006).

[93] J. A. Zimmerman, H. Gao, and F. F. Abraham, Generalized stacking fault energies for embedded atom fcc metals, Modell. Simul. Mater. Sci. Eng. 8, 103 (2000).

[94] S. Ogata, J. Li, and S. Yip, Energy landscape of deformation twinning in bcc and fcc metals, Phys. Rev. B 71, 224102 (2005).

[95] C. B. Carter and I. L. F. Ray, On the stacking-fault energies of copper alloys, Philos. Mag. 35, 189 (1977).
[96] V. E. Peissker, Critical stress for cross slip and stacking fault energies of copper base mixed crystals, Acta Metall. 13, 419 (1965).

[97] M. Muzyk, Z. Pakiela, and K. Kurzydlowski, Generalized stacking fault energy in magnesium alloys: Density functional theory calculations, Scr. Mater. 66, 219 (2012).

[98] J. Han, X. M. Su, Z. H. Jin, and Y. T. Zhu, Basal-plane stacking-fault energies of $\mathrm{Mg}$ : A first-principles study of Liand Al-alloying effects, Scr. Mater. 64, 693 (2011).

[99] S. Shang, W. Wang, B. Zhou, Y. Wang, K. Darling, L. Kecskes, S. Mathaud, and Z. Liu, Generalized stacking fault energy, ideal strength and twinnability of dilute Mg-based alloys: A first-principles study of shear deformation, Acta Mater. 67, 168 (2014).

[100] Y. F. Wu, S. Li, Z. G. Ding, W. Liu, Y. H. Zhao, and Y. T. Zhu, Effect of charge redistribution factor on stacking-fault energies of Mg-based binary alloys, Scr. Mater. 112, 101 (2016).

[101] A. Couret and D. Caillard, An in situ study of prismatic glide in magnesium II. Microscopic activation parameters, Acta Metall. 33, 1455 (1985).

[102] R. E. Smallmann and P. Dobson, Stacking fault energy measurement from diffusion, Metal. Trans. 1, 2383 (1970).

[103] A. J. Zaddach, C. Niu, C. C. Koch, and D. L. Irving, Mechanical properties and stacking fault energies of $\mathrm{NiFeCrCoMn}$ high-entropy alloy, JOM 65, 1780 (2013). 